\title{
Assessment of Longstanding Effects of Fly Ash AND Silica Fume on the Compressive STRENGTH OF CONCRETE Using EXTREME LEARNing MACHine AND ARTIFICIAL NeURAL NETWORK
}

\author{
Mahdi SHARIATI ${ }^{1, *}$, Danial Jahed ARMAGHANI' ${ }^{2}$ Manoj KHANDELWAL ${ }^{3}$, \\ Jian $\mathrm{ZHOU}^{4}$, Majid KHORAMI
}

\author{
${ }^{1}$ Faculty of Civil Engineering, University of Tabriz, Tabriz, Iran. \\ ${ }^{2}$ Department of Civil Engineering, Faculty of Engineering, University of Malaya, 50603, Kuala \\ Lumpur, Malaysia. \\ ${ }^{3}$ School of Engineering, Information Technology and Physical Sciences, Federation University \\ Australia, Ballarat, Australia. \\ ${ }^{4}$ School of Resources and Safety Engineering, Central South University, Changsha 410083, China. \\ ${ }^{5}$ Department of Mechanical Engineering, Politecnico di Milano, 20156 Milan, Italy. \\ *Corresponding Author: Mahdi SHARIATI (Email: shariati@tabrizu.ac.ir) \\ (Received: 14-Nov-2020; accepted: 18-Feb-2021; published: 31-Mar-2021) \\ DOI: http://dx.doi.org/10.25073/jaec.202151.308
}

\begin{abstract}
Compressive Strength (CS) is an important mechanical feature of concrete taken as an essential factor in construction. The current study has investigated the effect of fly ash and silica fume replacement content on the strength of concrete through Artificial Neural Networks (ANNs) and Extreme Learning Machine (ELM). In this study, different ratio of fly ash with (out) extra quantity of silica fume have been tested. Water cement $(w / c)$ ratio varies during the test. Eight input parameters including Total Cementitious Material (TCM), Silica Fume (SF) replacement ratio, coarse aggregate (ca), fly ash (FA) replacement ratio, Sewage Sludge Ash (ssa) as combination of cement and fine aggregate replacement, water cement ratio, High Ratio Water Reducing Agent (HRWRA) and Age of Samples (AS) and one output parameter as the CS of concrete have been investigated through $A N N$ and ELM. Up to now, numerous experimental studies have been used to analyze the
\end{abstract}

compressive strength of concrete while retrofitted with fly ash or silica fume, however, the novelty of this study is in its use of AI models (ELM, ANN). The models have been developed and their outcomes were compared through six statistical indicators (MAE, RMSE, RRMSE, WI, RMAE and $R^{2}$ ). Subsequently, both methods were shown as reliable tools for assessing the influence of cementitious material on compressive strength of concrete, however, ANN remarkably was better than ELM. As a result, FA showed less contribution to the strength of concrete at short times, but much at later ages. As a result, the enhanced influence of low amount of SF on CS was not significant. Adding fly ash has reduced the compressive strength in short term, but increased the compressive strength in longterm. Adding silica fume raises the strength in short term, but decreases the strength in long term. 


\section{Keywords}

Compressive strength, concrete, replacement material, extreme learning machine, artificial neural network.

\section{Introduction}

There are some demerits of cement production, such as using energy, high raw materials and heat. The production of cement makes air pollution by releasing gaseous emissions and huge solid waste materials. Cement manufacturing is complicated and high cost requiring high different amount and properties of materials, fuel sources such as fuel oil, tiers, natural gas, petroleum coke, coal, and pyro-processing techniques, such as preheating, recirculation and wet and dry kiln. Though, the cement production industry has made essential advances in decreasing CO2 emissions in its procedures, more improvement is confined, since $\mathrm{CO} 2$ production is inherent to the main processing of calcinating limestone [1]. Respectively, using aggregate could bring many benefits as low cost, Eco-friendly, Versatile and durable. Also, aggregate is significant for strength, dimensional stability, thermal - elastic properties of concrete and volume stability. Cement is more likely to be affected by shrinkage, however, aggregates could reduce the shrinkage level and prevent cracking. The compressive aggregate strength is another significant parameter in selection of aggregate. Comparing the normal concrete strength with the strength of concrete exposed by aggregates, the later sounds stronger than the conventional concrete. Using aggregates in concrete assist the conserving of raw materials, reduction of carbon dioxide emissions and finally lower environmental pollution beside bringing more sustainability in construction [2]. Among all, silica fume (SF) and fly ash are the two supplementary cementitious aggregates with pozzolanic characteristics (Demirboga et al., 2001; Bilodeau and Malhotra, 2000) carrying economical, ecological and technical benefits $[3,4]$. SF is a byproduct of producing ferrosilicon alloys or silicon metal due to is its physical and chemical properties as a very reactive pozzolan (Khedr and AbouZaid 1(94)) [5]. By using silica fume in concrete in Canada, it was considered as a cement replacement in normal strength concrete in order to gain a favorite 28-day CS [2]. Some studies have researched the improvement of CS in hardened concrete through SF (Iravani, 1996; Khedr and Abou-Zeid, 1994; Atis, et al., 2005; Toutanji and Bayasi, 1999; Khatri and Sirivivatnanon, 1995; Sabir, 1995; Detwiler and Mehta, 1989; Mazloom et al., 2004; Xie et al., 1995; Cetin and Carrasquillo, 1998; Goldman and Bentur, 1993; Hooton, 1993; Zhou et al., 1995; Yogendran et al., 1987) [5-19]. On the other hands, SF is able to advance the physical and chemical properties while transforming the microstructure of concrete and mightily increase the strength and reduce the permeability (Elahi et al., 2010) [20]. SF could improve the abrasion resistance and durability of concrete (Malhotra and Mehta, 1996; Dotto et al., 2004; Behnood and Ziari, 2008; Laplante et al., 1991) [21-23], improving the resistance of concrete against sulfate attack and acid (Türker et al., 1997; Aköz et al., 1995, 1999) [24-26] and improving the bond between the aggregate and the paste (Khatri et al., 1997; Al-Khaja, 1994; Alexander and Magee, 1999) [10, 27, 28]. These all make SF the most available mineral mixture for high-strength concrete (Poon et al., 2006) [29].

Fly ash is also a waste material derived from the combustion of pulverized coal in electricity generating plants Fly ash particles are generally solid glassy spheres, from grey to tan to reddish brown and range in size from $2 \mu \mathrm{m}$ to $10 \mu \mathrm{m}$. Fly ash is the unburned residue carried away from the burning zone in the boiler by the flue gases and then gathered by electrostatic or mechanical separators [31-33]. It comprises mostly aluminum oxide (Al2O3), iron oxide (Fe2O3) and silicon dioxide (SiO2) [34]. Despite the common use of fly ash over 50 years, there are confinements over its usage in concrete due to unknown characteristics of fly ash in concrete $[35,36]$ which is highly based on the type of applied coal, temperature of fire, air fuel ratio, the combustion condition and collector setup [37-40]. In this case, some generalized processing is made in surface area, morphology, density, distribution of particle size, hydraulic conductivity or permeability of fly ash [41]. Gen- 
Tab. 1: The properties of silica fume and cement (Fuat Ko“ksal, Fatih Altun, et al., 2008) [30].

\begin{tabular}{|l|l|l|}
\hline Composition(\%) & Cement & $\begin{array}{l}\text { Silica } \\
\text { fume }\end{array}$ \\
\hline $\begin{array}{l}\text { Chemical composi- } \\
\text { tion }\end{array}$ & & \\
\hline $\mathrm{SiO}_{2}$ & 19.12 & 81.35 \\
\hline $\mathrm{Al}_{2} \mathrm{O}_{3}$ & 5.63 & 4.48 \\
\hline $\mathrm{Fe}_{2} \mathrm{O}_{3}$ & 2.39 & 1.42 \\
\hline $\mathrm{CaO}$ & 63.17 & 0.80 \\
\hline $\mathrm{MgO}$ & 2.75 & 1.47 \\
\hline $\mathrm{SO}_{3}$ & 2.74 & 1.34 \\
\hline $\mathrm{Na}_{2} \mathrm{O}$ & & \\
\hline $\mathrm{K}_{2} \mathrm{O}$ & 1.00 & \\
\hline Insoluble material & 0.49 & \\
\hline Loss on ignition & 2.33 & 3.4 \\
\hline & & \\
\hline Physical properties & & \\
\hline Specific gravity & 3.09 & 2.23 \\
\hline $\begin{array}{l}\text { Specific surface } \\
\text { (cm }{ }^{2} / g \text { g) }\end{array}$ & 3114 & \\
\hline
\end{tabular}

erally, fly ash comprises two classes as fly ash Class C and fly ash Class F. Fly ash from class C typically is made from the combustion of subbituminous coal or younger lignite, however, fly ash class $\mathrm{F}$ is made from the burning of older anthracite and harder bituminous coal. The major alteration between the two classes is the amount of alumina, silica, iron, and calcium content. Class F fly ash consist of less than $10 \% \mathrm{CaO}$ and minimum $\mathrm{Al} 2 \mathrm{O} 3+\mathrm{Fe} 2 \mathrm{O} 3+\mathrm{SiO} 2$ content of $70 \%$, whereas Class $\mathrm{C}$ fly ash consist of more than $20 \% \mathrm{CaO}$ and minimum $\mathrm{Fe} 2 \mathrm{O} 3+\mathrm{Al} 2 \mathrm{O} 3$ $+\mathrm{SiO} 2$ content of $50 \%[32,42]$. Kearsley and Wainwright (2001) have investigated the influence of fly ash on CS of concrete, finding that CS is highly depending on the fly ash dry density [43]. It was also found that the high replacement ratio of fly ash instead of cement couldn't significantly impact the concrete's strength in long term (Kearsley and Wainwright, 2001). In another study by Behnood and Golafshani (2018), ANN is used with Multi-Objective Grey Wolves (HANNMOGW) method to predict the CS of silica fume concrete, resulting a linear increment in the CS of silica fume concrete when the silica fume to binder ratio is raised from 0 to approximate $30 \%$. Also, the CS of silica fume concrete is significantly affected by the maximum aggregate size [44]. Pala et al. (2007) has tested the influence of silica fume and fly ash replacement on the concrete's strength cured for a long time by neural networks (NNs) with various water cement ratio, with(out) the extra low SF content and low \& high FA volume, in which the enhancement impact of low SF content on CS was not significant. Thus, FA was contributed low at early ages, but much at later ages to the strength of concrete, also showing NNs as a reliable tool to assess the impact of cementitious material on the CS of concrete [45].

Artificial Intelligence (AI) is commonly applied to estimate and predict CS and other mechanical features of concrete mixes (Golafshani and Behnood, 2018a, 2018b; Erdal, 2013; Ha et al., 2017; Behnood et al., 2017, 2015b, 2015c; Cheng et al., 2014; Golafshani and Ashour, 2016) [51-59]. Table 3 shows some samples of the methods that was previously applied to estimate the CS of various concrete types.

ANN (as an artificial intelligence) is commonly applied for predicting different properties of concrete mixtures by solving very rigorous problems through the interconnected computing elements. ANN process resembles the brain network including many simple computational parameters arranged in layers. A concrete designed by ANN is expected to have optimal water and cement that should bring more durability and likely better ecological and economic impacts [63]. Neural networks (NN) could "learn" and "correlate" the large datasets gained from simulations and tests. A trained NN performs as an analytical tool for the qualified prognoses of real outcomes, showing highly accurate scores in their predictions. Asteris and Mokos (2019) have used ANN to predict the CS of concrete with ultrasonic pulse velocity. Thus, ANN showed the capability to approximate the CS of concrete [73]. ELM is also a new model to train ANN while demonstrating good generalization performance and fast learning speed in many regression usages. Al-Shamiri et al (2019) has used ELM for predicting the CS of high strength concrete (HSC) [74]. The performance of developed ELM has been compared to that of ANN trained. The simulation results have shown ELM as a strong potential for the predic- 
Tab. 2: Physical properties of Fly Ash [46].

\begin{tabular}{|c|c|c|c|c|}
\hline Property & $\begin{array}{lll}\text { Maher \& } & \text { Bal- } \\
\text { aguru } & & \\
(1993) & {[47]} & \end{array}$ & $\begin{array}{l}\text { Mitash N } \\
(2007)[48]\end{array}$ & $\begin{array}{l}\text { Huang et al } \\
(1995) \text { [49] }\end{array}$ & $\begin{array}{l}\text { Muhardi et al } \\
\text { (2010) [50] }\end{array}$ \\
\hline Specific gravity & 2.54 & $1.9-2.55$ & 2.06 & 2.3 \\
\hline Moisture content & $13.60 \%$ & & $0.53 \%$ & $19.75 \%$ \\
\hline Fineness & & & $\begin{array}{l}13.80 \% \text { in } \\
\text { No. } 325\end{array}$ & $0.6-0.001 \mathrm{~mm}$ \\
\hline LOI & & & 7.5 & \\
\hline Maximum dry density & $1.65 \mathrm{~g} / \mathrm{cm}^{3}$ & $0.9-1.6 \mathrm{~g} / \mathrm{cm}^{3}$ & & $1.53 \mathrm{~g} / \mathrm{cm}^{3} \mathrm{cc}$ \\
\hline Uniformity coefficient & 2.5 & $3.1-10.7$ & & \\
\hline Liquid limit & 16.8 & & & \\
\hline Permeability & $0.9 \times 10^{-5} \mathrm{~cm} / \mathrm{s}$ & $10^{-5}-10^{-3} \mathrm{~cm} / \mathrm{s}$ & & $\begin{array}{l}4.87 \times 10^{-7} \\
\mathrm{~cm} / \mathrm{s}\end{array}$ \\
\hline $\begin{array}{l}\text { Angle of internal } \\
\text { friction }\end{array}$ & & $30^{\circ}-40^{\circ}$ & & $23^{\circ}-41^{\circ}$ \\
\hline Cohesion & & Negligible & & $3-34 \mathrm{kPa}$ \\
\hline Compression index & & $0.05-0.4$ & & 0.15 \\
\hline $\begin{array}{l}\text { Coefficient of consoli- } \\
\text { dation }\end{array}$ & & & & $\begin{array}{l}0.1-0.5 \\
\mathrm{~m}^{2} / \text { year }\end{array}$ \\
\hline
\end{tabular}

Tab. 3: AI methods applied to predict the CS of different concrete types [44].

\begin{tabular}{|l|l|}
\hline Concrete type & AI models \\
\hline Normal concrete & $\begin{array}{l}\text { Artificial Neural Network (ANN) (Uddin et al., 2017), Evolu- } \\
\text { tionary } \\
\text { ANN (Nikoo et al., 2015) [60, 61] }\end{array}$ \\
\hline High-performance concrete & $\begin{array}{l}\text { ANN (Atici, 2011; Prasad et al., 2009; Yeh, 1998) [62-64], Mul- } \\
\text { tiple Additive Regression Tree (MART) (Chou et al., 2011) } \\
\text { [65], bagging regression trees (Chou et al., 2011) [65], M5P tree } \\
\text { model (Behnood et al., 2017; Deepa et al., 2010) [55, 66], Multi- } \\
\text { variate regression analysis (Atici, 2011) [62], Genetic operation } \\
\text { tree (Yeh and Lien, 2009) [64], Decision tree (Erdal, 2013) [53], } \\
\text { Evolutionary } \\
\text { ANN (Bui et al., 2018) [67] }\end{array}$ \\
\hline Fly ash concrete & $\begin{array}{l}\text { ANN (Topçu and Sarıdemir, 2008) [68], Fuzzy logic models } \\
\text { (Topçu and Sarıdemir, 2008) [68], Fuzzy polynomial neural net- } \\
\text { works (Fazel Zarandi et al., 2008) [69] }\end{array}$ \\
\hline $\begin{array}{l}\text { GNound granulated blast } \\
\text { furnace slag concrete }\end{array}$ & $\begin{array}{l}\text { ANN (Naderpour et al., 2018) [71], Genetic programming } \\
\text { (Velay-Lizancos et al., 2017) [72], M5P tree model (Behnood } \\
\text { et al., 2015a) [56] }\end{array}$ \\
\hline Recycled aggregate concrete \\
ANN (Prasad et al., 2009) [63] \\
\hline Self-compacting concrete
\end{tabular}

tion of the CS of high strength concrete (HSC). In another study, Yaseena et al (2013) has used M5 Tree, MARS, ELM, and SVR learning models to predict the CS of lightweight foamed con- crete that the results showed ELM more accurate than pother four models [75]. The current study, by use of AI models has attempted to provide a precise analysis in predicting the compres- 
sive strength of concrete while exposed by fly ash and silica fume. Many studies have analyzed the addition of aggregates to concrete, however, using AI models is rarely seen. Accordingly, this research has attempted to provide a precise and accurate analysis to the case. This study has used ANN and ELM align with the objective of this study in terms of using AI models to predict the compressive behavior of concrete while adding aggregates. In the following, the models have been developed and their results were illustrated in diagrams. Comparing this study with the original one that data was derived from is in methodology. While the original paper only used one AI model (neural network), the current study has used two AI models for the same analysis of adding fly ash and silica fume to concrete.

\section{Problem Statement and Objective}

Regarding the concrete content (chemical admixtures, water, supplementary cementitious materials, fine and coarse aggregates, cement and fibers), one big problem is to achieve and maintain the specified CS in concrete design. Due to the low knowledge in terms of the tests between concrete strength and its constituents, finding the reliable and novel machine learning methods and soft computing to gain those relationships has been provoked [75]. Having to try all the different quantities and testing each one's performance takes enormous time, effort, cost and might with less accuracy (experimental error). To capture a 28-day design CS with proper workability, the technical personnel have to highly attempt for several mix percentages that takes long time, raising the wastage of material and cost of concrete production. Significantly, in case of concrete test failures after so long waiting, there might be highly difficult to adjust another test as before. On the other hand, for improving the strength and sustainability of concrete, using aggregates, such as silica fume, fly ash and slag are highly applied from the last few decades. In this case, there are many models for prediction and estimating the strength of concrete well before 28 days as Abrahams Law [76]. However, in reality, the relationship between the strength of concrete and its constituent's material is highly nonlinear and Abrahams Law model is failed satisfactorily to compute this complicated relationship and falling short to generalize the unseen data. Unlike Abrahams Law, AI was proved as reliable and accurate tool in learning rigorous patterns, besides saving time and money. Among AI algorithms, ANN is broadly suggested to predict the strength of concrete through the use of back propagation (BP) network. Adding that $\mathrm{BP}$ fails from the local minima that is led to the instability in the developed model. The convergence to local minima is due to the optimization objective of ANN that is naturally multimodal. It is due to the fact that various training data sets generate various models affecting the capability of that model in generalizing to previously unseen data. It could be a confinement to ANN reported in the related studies particularly in medical estimation and predictions [77]. Though there might be a solution to this by aggregating the outputs of few models developed from the training data as "boosting", "bagging" or stacking predictors, this brings more computations and some uncertainty [78, 79]. The use of nontuned machine learning model e.g. ELM could bring high progress in multidisciplinary of engineering and science fields in past few years. This is due to its superiority on standard ANN algorithms, such as the randomly initiated hidden neurons without the need for iterative tuning process for free parameters or connections between hidden and output layers. ELM as a relatively new learning method for feedforward NNs, unlike conventional NNs, the hidden biases and input weights are randomly initialized and remain fixed across the learning process plus the analytically determination of output weights, all bring to ELM a good generalized performance and fast learning speed [74]. Ultimately, ELM is highly proficient in gaining a global optimum while following global approximating capability of single layer feed-forward network. Also, ELM is superior because of its generalized performance in estimating problems in various fields than the conventional models as ANNs or SVMs. On the other hand, ANN is better than the multiple regression ones, particularly in decreasing the scatter of predictions in concrete mixture. ANN has been widely used in predicting the self-compacting concrete (SCC), CS of conventional concrete and high performance concrete (HPC). Then, ANN is able to predict the CS of 
flowable concrete in an appropriate admixture of concrete.

\section{Methodology}

The data of this research was originally obtained from the study of "Appraisal of long-term effects of fly ash and silica fume on CS of concrete by neural networks" including 144 various concrete mixtures. Water cement $(\mathrm{w} / \mathrm{c})$ ratio was differed during the test comprising the high and low FA content and with(out) extra small SF content. Accordingly, 24 various mixtures with 144 various samples have been collected from a previous study. The concrete of samples was cured for 3 , 7, 28, 56 and 180 days (Appendix 1) (Tab. 4) [45].

\subsection{Statistical data}

Table 4 shows the input and output parameters used in this investigation. including silica fume replacement ratio (SF), total cementitious material (TCM), coarse aggregate (ca), water content (W), fly ash replacement ratio (FA), fine aggregate (ssa), age of samples (AS), high rate water reducing agent (HRWRA) and one output parameter as compressive strength of concrete (fc).

Tab. 4: Input - output parameters in database.

\begin{tabular}{|l|l|}
\hline Inputs & Parameters description \\
\hline input 1 & $\mathrm{FA}(\%)$ \\
input 2 & $\mathrm{SF}(\%)$ \\
input 3 & $\mathrm{TCM}\left(\mathrm{kg} / \mathrm{m}^{3}\right)$ \\
input 4 & $\mathrm{ssa}\left(\mathrm{kg} / \mathrm{m}^{3}\right)$ \\
input 5 & $\mathrm{ca}\left(\mathrm{kg} / \mathrm{m}^{3}\right)$ \\
input 6 & $\mathrm{W}\left(\mathrm{lt} / \mathrm{m}^{3}\right)$ \\
input 7 & $\mathrm{HRWRA}\left(\mathrm{lt} / \mathrm{m}^{3}\right)$ \\
input 8 & Age $($ days $)$ \\
output & fc $(\mathrm{MPa})$ \\
\hline
\end{tabular}

\subsection{Artificial Neural Network (ANN)}

ANN, a common multilayer algorithm, is derived by the biological NN of humans/animals [80, 81].
Through the mechanism of layers, ANN could solve adequate complications for estimating targets in multi-dimensional space of problems [79, 82]. Multilayer perceptron (MLP) is a practical and simple class of feed forward ANN [83, 84]. one MLP includes one input layer, one hidden layer and one output layer [85]. Input layer takes the predictive data and transfers them to the available neurons in the next (hidden) layer. In the Input layer, biases are added, weights are multiplied and a net value is calculated [86], [87] as Eq. (1):

$$
N e t=\sum_{i=1}^{n} w_{i j} x_{i}+b_{j}
$$

$x_{i}=$ nodal variables in previous layer

$n=$ all nodal variable' numbers received from the previous layer

$w_{i j} \& b_{j}=$ the weights and biases of network in the current layer

In order to decrease the net values' diversity, an activation function is used to the net, then $y$ as output signal was reported [88]. The tangent hyperbolic function is regarded as the highest reliable activation performances as Eq. (2):

$$
y=f(N e t)=\frac{2}{1+e^{-2 . N e t}}-1
$$

This process is performed on each layer of MLP until the output signals of the last layer (predicted values) are reported. Later, the differential of the observed variables (error) and predicted ones have been computed. Ultimately, one optimized algorithm is used to decline the error variable by modifying the assigned biases and weights through MLP. This training procedure can be performed through diverse algorithms, however, due to the high speed of convergence and high accuracy of backpropagation algorithms, ANN is more preferable in this study [89]. Fig. 1 indicates the scheme of an ANN.

\subsection{Extreme Learning Machine (ELM)}

Huang et al. proposed ELM to tune the single layer feed forward NN (SLFNN) architectures [90]. ELM is derived from the notion that an 


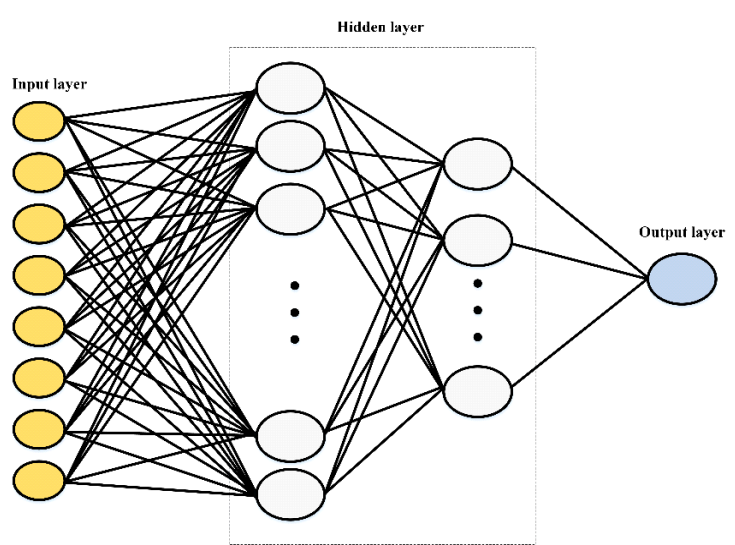

Fig. 1: ANN structure.

SLFNN with random biases and weights is able to predict any continuous function at any compact input set [91, 92]. Three phases are worked in ELM development as: 1) generation of one SLFNN, 2) randomly selection of weights and biases of network and 3) estimation of output weights by inverting the hidden layer output matrix $[74,93]$. For a dataset including $m$ dimensional target vectors, $n$ dimensional input vectors and $N$ training samples, one SLFNN with $L$ hidden nodes could be computed as Eq. (3) [94, 95]:

$$
\sum_{i=1}^{L} \beta_{i} G\left(w_{i} . x_{j}+b_{i}\right)=o_{j} \quad j=1,2,3, \ldots, N
$$

$G=$ the activation performance (all the NN based activation functions could be applied here as well)

$w_{i}=\left[w_{i 1}, w_{i 2}, \ldots, w_{i n}\right]^{T}=$ weight vector connecting $i^{\text {th }}$ input neurons to hidden neuron $x_{j}=\left[x_{j 1}, x_{j 1}, \ldots, x_{j m}\right]^{T}=$ input vector $\beta_{i}=\left[\beta_{i 1}, \beta_{i 2}, \ldots, \beta_{i m}\right]^{T}=$ weight vector connecting output neurons to hidden neurons $b_{i}=\left[b_{i 1}, b_{i 2}, \ldots, b_{i m}\right]^{T}=$ bias vector $o_{j}=\left[o_{j 1}, o_{j 1}, \ldots, o_{j m}\right]^{T}=$ output vector

Supposing that an SLFNN with $L$ hidden neurons and activation function $G$ could compute the targets $\left(t_{j}\right)$ with 0 error, i.e. $\sum_{j=1}^{L}\left\|o_{j}-t_{j}\right\|=0$, Eq. (3) can be modified to
Eq. (4):

$\sum_{i=1}^{L} \beta_{i} G\left(w_{i} . x_{j}+b_{i}\right)=t_{j} \quad j=1,2,3, \ldots, N$

$t_{j}=\left[t_{j 1}, t_{j 2}, \ldots, t_{j m}\right]^{T}=$ target vector

Also, this $N$ equations could be compactly written as:

$$
H \beta=T
$$

in which:

$H=$

$$
\left[\begin{array}{ccc}
G\left(w_{1}+x_{1}+b_{1}\right) & \ldots & G\left(w_{L} \cdot x_{1}+b_{L}\right) \\
\vdots & \ldots & \vdots \\
G\left(w_{1}+x_{N}+b_{1}\right) & \ldots & G\left(w_{L} \cdot x_{N}+b_{L}\right)
\end{array}\right]_{N \times L}
$$

and,

$$
\beta=\left[\begin{array}{c}
\beta_{1}^{T} \\
\vdots \\
\beta_{L}^{T}
\end{array}\right]_{L \times m} \text { and } T=\left[\begin{array}{c}
t_{1}^{T} \\
\vdots \\
t_{N}^{T}
\end{array}\right]_{N \times m}
$$

The output weights are gained if the minimal differential between the right side (target variables) and the left side (predicted variables) of Eq. (5) is occurred e.g. min $\|\mathrm{H} \beta-\mathrm{T}\|$. Based on the mathematical theories, it was proved that when the output weight is as follows, the minimal error between the target variables and predicted variables occurs:

$$
\widehat{\beta}=H^{\dagger} T
$$

$\widehat{\beta}=$ output weight vector

$H^{\dagger}=$ Moor-Penrose generalized inverse matrix $T=$ target vector

As noted, no optimization process is involved in ELM, then the human inferences and the training time are reduced efficiently. The components of ELM are shown in Fig. 2.

\section{Results and Discussions}

For evaluating and testing the models' performance used in this research, $70 \%$ of the data is randomly separated and assigned to training section, and $30 \%$ data is used to testing phase. As 


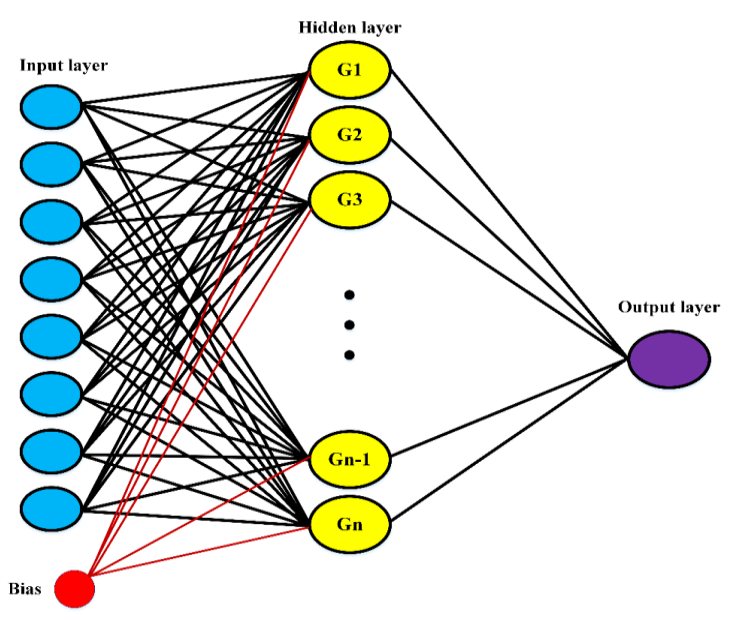

Fig. 2: ELM structure.

a measurement parameter, statistical model performance indicators comprising mean absolute error $(M A E)$, root mean square $(R M S E)$, relative root mean squared error (RRMSE), Willmott's index $(W I)$, relative mean absolute error $(R M A E)$ and determination coefficient $\left(R^{2}\right)$ were applied.

$$
\begin{gathered}
R^{2}=\frac{\left[\sum_{i=1}^{N}\left(O_{i}-\bar{O}\right) \cdot\left(P_{i}-\bar{P}\right)\right]^{2}}{\sum_{i=1}^{N}\left(O_{i}-\bar{O}\right) \cdot \sum_{i=1}^{N}\left(P_{i}-\bar{P}\right)} \\
R M S E=\sqrt{\sum_{i=1}^{N} \frac{1}{N}\left(O_{i}-P_{i}\right)^{2}} \\
M A E=\frac{1}{N} \sum_{i=1}^{N}\left|O_{i}-P_{i}\right| \\
R R M S E=\frac{R M S E}{\bar{O}} \cdot 100 \\
R M A E=\frac{M A E}{\bar{O}} \cdot 100 \\
W I=1-\left[\frac{\sum_{i=1}^{N}\left(O_{i}-P_{i}\right)^{2}}{\sum_{i=1}^{N}\left(\left|P_{i}-\bar{O}\right|+\left|O_{i}-\bar{O}\right|\right)^{2}}\right]
\end{gathered}
$$

$N=$ the number of testing $\mathrm{r}$ training samples

$O_{i}=$ observed values in sample $i$

$P_{i}=$ predicted values in sample $i$

$\bar{O}=$ the mean observed variables

$\bar{P}=$ the predicted values

For comparing the models, all codes are written in MATLAB without using external toolbox or compiler. Afterwards, codes were computed a processor (Intel(R) Core (TM) i5-8250U CPU 1.60 GHz 1.80 GHz and 8.0 GB RAM).

\section{Developing of Models}

\section{1) ANN Development}

The performance of ANN obviously is based on the layout and model's architecture, say the neurons' number and the hidden layers' number used in each layer. An error and trail processing was performed to gain the desired performance in order to find the appropriate ANN architecture. Altered architectures with different neurons and hidden layers have been made while each model was run 3 times with $\mathbf{8 0 0}$ epochs. This is because in AI models generally and ANN particularly, data are selected randomly in test and train phases (70\% train, 30\% test), so probably the neurons that are going to predict the output could provide a good prediction (or not). For reducing the probability of randomness and avoiding the adverse effect on our output, data is run three times, then the average of three times is selected as the output. In Tabs. 5 and 6, the RMSE values show the average of the data after three runs. In this research, LevenbergMarquardt (LMA) was applied to define the bias and weight of ANN neurons due to its fast performance in achieving optimal performance among BP algorithms. Finally, the mean value of $R M S E$ was achieved to indicate the performance of models and their comparison. Table 5 shows the $R M S E$ variables (single-layer) of ANN in trial and error processing that was modified for each layer and neurons number. Figure 3 shows the RMSE output of ANN with the neurons $1,2,3, \ldots 10$ as single-layer in testing and training phases. According to Tab. 6 and Fig. 4, there are 6 neurons in the first layer and 4 neurons in the second layer with the $R M E S$ values of 1.534524 and 2.208552 in training and testing phase, respectively. Since there weren't good results in the $R M S E$ values of the single-layer, then the second layer was used and provided good results. Though few models with altered combinations of layers and neurons gain lower $R M S E$ variable in training phase, they are not able to gain this performance in testing phase. Figure 4 shows the both layers (single and two- 
layer) in ANN model while the first layer has 6 neurons and the second layer has 4 neurons. It is noted that when the RMSE of test was increasing, it is not good for accurate prediction, so adding neuron was stopped in testing phase and the least amount was taken as the best result. Thereafter, adding neuron in the second layer was stopped and point $\mathbf{x}$ (Fig. 4) with 6 neurons in the first layer and 4 neurons in the second layer is accepted as the best $R M S E$ point and the best ANN performance in the second layer. As a result, ANN couldn't represent good performance in the first layer (single-layer), however, it showed its best performance in the second layer (two-layer). Considering the innovation of using ANN, data was initially analyzed in the first layer and the output was obtained (Fig. 3). Later, the same process was performed in the second layer (Fig. 4), showing the best performance of ANN in the second layer (point $\mathbf{x}$ ).

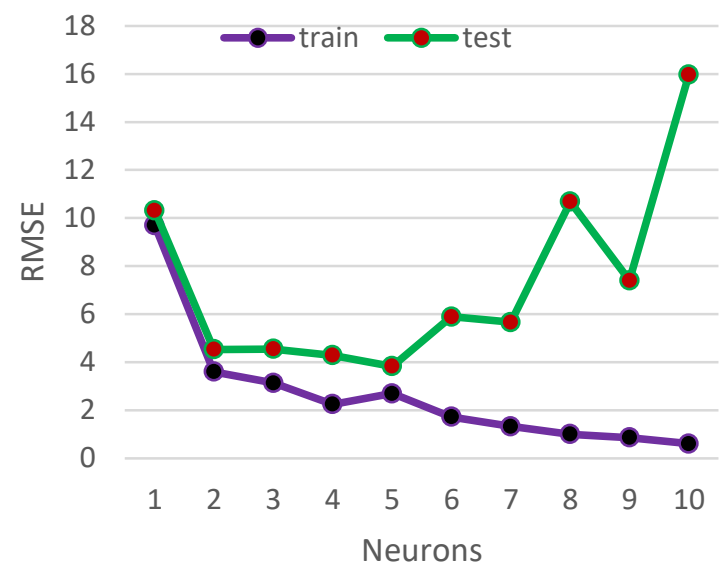

Fig. 3: The graphical picture of single-layer of ANN in training and testing phase.

\section{ANN Results:}

Following Tab. 5, the monolayer arrangement of neurons is tested and the results is depicted in Fig. 3 in training and testing phases.

Table 6 shows the two-layer arrangement along the training and testing results. Figure 4 shows the best (lowest) RMSE in testing and training phases.

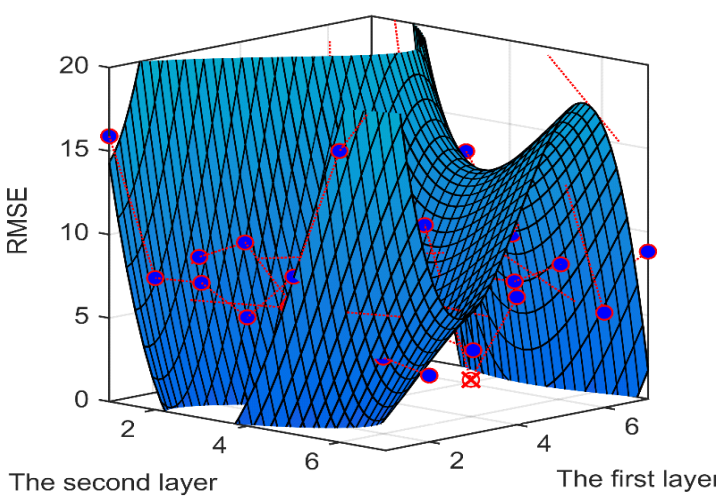

Fig. 4: Two-layer ANN and the best RMSE point in testing phase.

Tab. 5: $R M S E$ variables of ANN in trial and error processing (Single-layer).

\begin{tabular}{|l|l|l|}
\hline First layer & train & test \\
\hline 1 & 9.707343 & 10.32235 \\
\hline 2 & 3.604467 & 4.535212 \\
\hline 3 & 3.14094 & 4.549322 \\
\hline 4 & 2.254623 & 4.288685 \\
\hline 5 & 2.702086 & 3.828284 \\
\hline 6 & 1.725994 & 5.894069 \\
\hline 7 & 1.328079 & 5.666384 \\
\hline 8 & 1.008558 & 10.68123 \\
\hline 9 & 0.866963 & 7.406495 \\
\hline 10 & 0.613574 & 15.97062 \\
\hline
\end{tabular}

Tab. 6: The RMSE values of ANN in two layers in training and testing phases (Full date is in appendix 2).

\begin{tabular}{|l|l|l|l|}
\hline $\begin{array}{l}\text { First } \\
\text { layer } \\
\text { neuron }\end{array}$ & $\begin{array}{l}\text { Second } \\
\text { layer } \\
\text { neuron }\end{array}$ & Train & Test \\
\hline 2 & 4 & 1.389969 & 6.713467 \\
\hline 3 & 4 & 0.644357 & 6.445502 \\
\hline 4 & 4 & 0.563873 & 10.68091 \\
\hline 5 & 4 & 0.95852 & 10.96912 \\
\hline 6 & 4 & 1.534524 & 2.208552 \\
\hline 7 & 4 & 0.914569 & 7.634039 \\
\hline 8 & 4 & 1.287565 & 4.734597 \\
\hline 9 & 4 & 1.163599 & 9.779257 \\
\hline 10 & 4 & 0.38738 & 19.30937 \\
\hline 1 & 5 & 1.148456 & 293.8489 \\
\hline
\end{tabular}




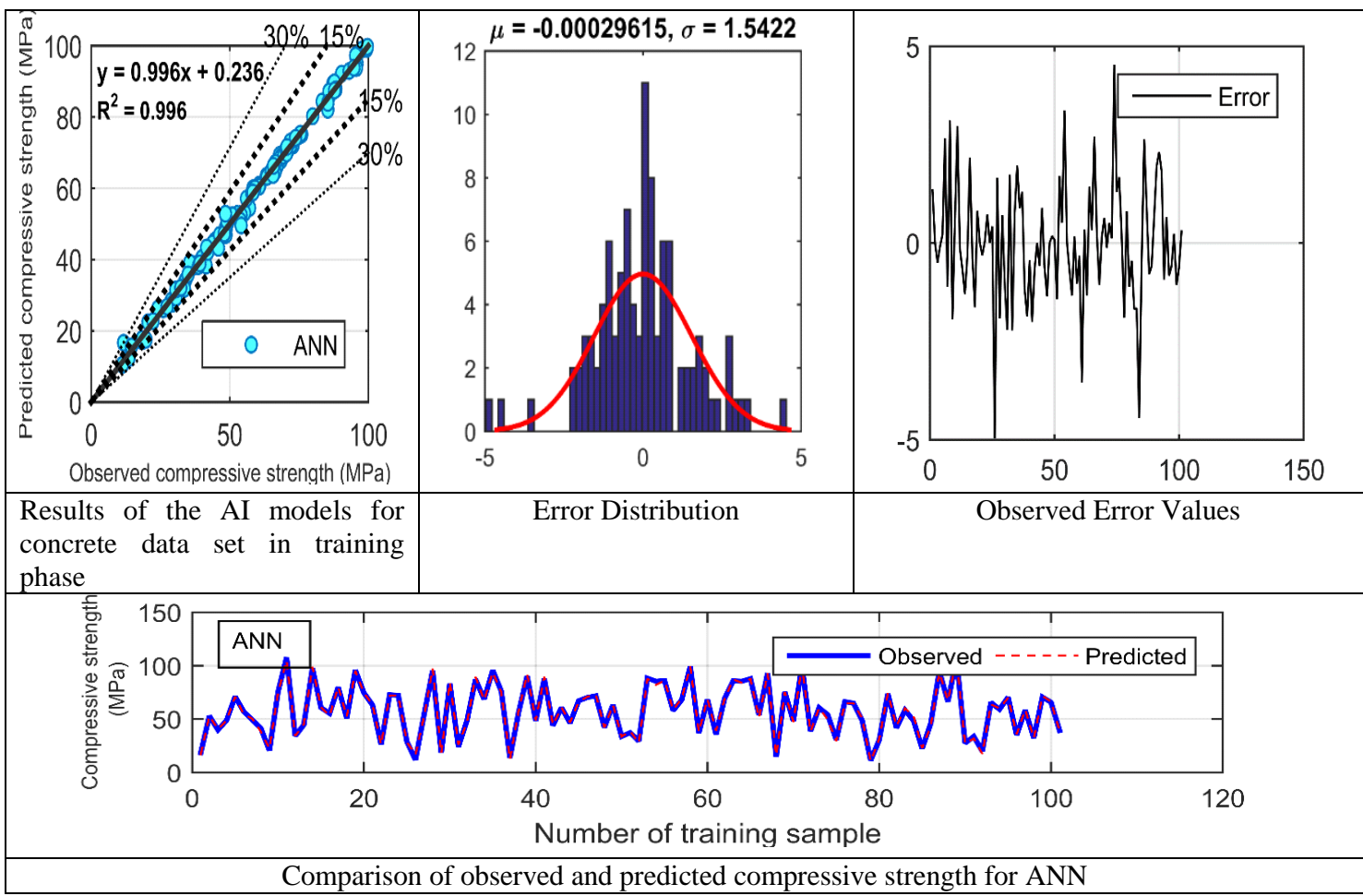

Fig. 5: ANN model training outputs.

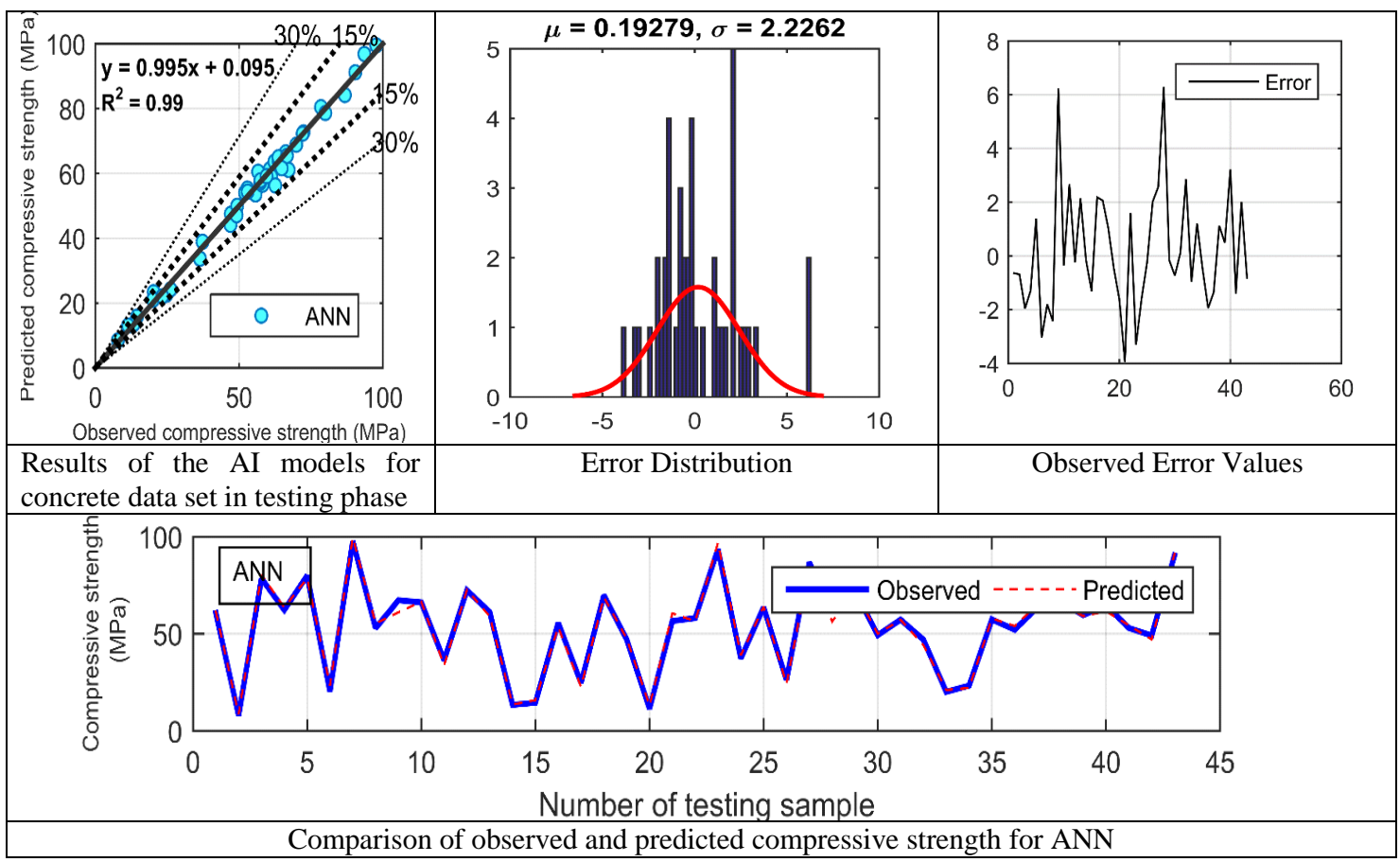

Fig. 6: ANN model testing outputs. 


\section{2) ELM Development}

Unlike ANN, ELM deals with single layer feed forward neural network (SLFNN) architectures. There is no need to define the hidden layers' number, then SLFNN was determined and leads to the network architecture parameter specifying. A trial and error process (such as ANN) has been carried out to specify the number of ELM neurons. Subsequently, ELM performance is tested by the RMSE index during the training and testing steps in this trial and error process. Table 7 shows the RMSE of ELM model in trial and error process with their corresponding variables as one layer. By adding the neurons' amount, it is not good for accurate prediction, so 67 neurons were stabled. Since ELM is involved with only one layer, considering all the $R M S E$ values in this layer, the architecture with 67 neurons and the RMSE value of 4.6025 in testing phase is accepted as the best performance of ELM. Figure 7 shows the RMSE output of ELM with the neurons of $50,52,54, \ldots 80$ as one hidden layer in testing and training phases. Considering the innovation of ELM, based on different neurons, output was obtained (Fig. 7), showing that the architecture of 67 was the best performance of single layer ELM. In terms of cost for both models, ANN designing takes more cost and accuracy due to its layers than ELM with one layer.

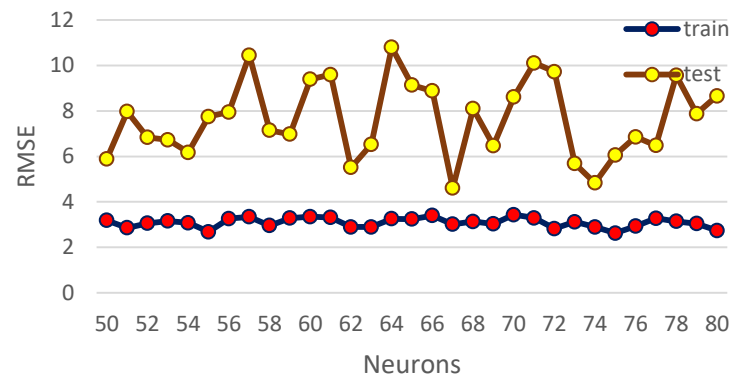

Fig. 7: The graphical picture of ELM in testing and training phase.

Table 7 shows the $R M S E$ values in training and testing results for the number of neurons in ELM model.

After analyzing the involved parameters in ANN and ELM, both were run and their function in term of previously performance metrics
Tab. 7: $R M S E$ values in trial and error process.

\begin{tabular}{|l|l|l|}
\hline Nu. & Train & Test \\
\hline 50 & 3.190231 & 5.891087 \\
\hline 51 & 2.862159 & 7.968922 \\
\hline 52 & 3.059752 & 6.831718 \\
\hline 53 & 3.156456 & 6.729685 \\
\hline 54 & 3.079353 & 6.174658 \\
\hline 55 & 2.683887 & 7.74737 \\
\hline 56 & 3.263969 & 7.945308 \\
\hline 57 & 3.342795 & 10.44598 \\
\hline 58 & 2.957656 & 7.148689 \\
\hline 59 & 3.287528 & 6.978607 \\
\hline 60 & 3.346792 & 9.39127 \\
\hline 61 & 3.311584 & 9.591771 \\
\hline 62 & 2.893009 & 5.514078 \\
\hline 63 & 2.898763 & 6.528791 \\
\hline 64 & 3.255487 & 10.79586 \\
\hline 65 & 3.245989 & 9.12994 \\
\hline 66 & 3.39783 & 8.878136 \\
\hline 67 & 3.0196 & 4.6025 \\
\hline 68 & 3.134022 & 8.09941 \\
\hline 69 & 3.030526 & 6.468871 \\
\hline 70 & 3.435698 & 8.604487 \\
\hline 71 & 3.295331 & 10.10774 \\
\hline 72 & 2.822732 & 9.719424 \\
\hline 73 & 3.11962 & 5.681063 \\
\hline 74 & 2.899568 & 4.8361 \\
\hline 75 & 2.629813 & 6.058653 \\
\hline 76 & 2.933741 & 6.851958 \\
\hline 77 & 3.281796 & 6.47999 \\
\hline 78 & 3.145036 & 9.556516 \\
\hline 79 & 3.043555 & 7.876588 \\
\hline 80 & 2.740894 & 8.654041 \\
\hline & & \\
\hline 5
\end{tabular}

have been assessed in training and testing phases of the two models (Table 8, 9). Comparing the ANN and ELM performance, the values of $R M S E$ and $\mathrm{R}^{2}(R S Q R)$ is compared in testing phase. Obviously, the best $R M S E$ value is the one that is near to 0. Accordingly, by comparing the RMSE of ANN (2.2086) and ELM (4.6025), it is proved that the RMSE of ANN is near to 0 , then the best performance metrics belong to ANN than ELM in predicting the CS of concrete in adding silica fume and fly ash. On the other hand, the more $R^{2}(R S Q R)$ value is near to 1 , the more it is acceptable. In this case, the $R^{2}$ values of both ANN (0.9905) and ELM (0.9616) 


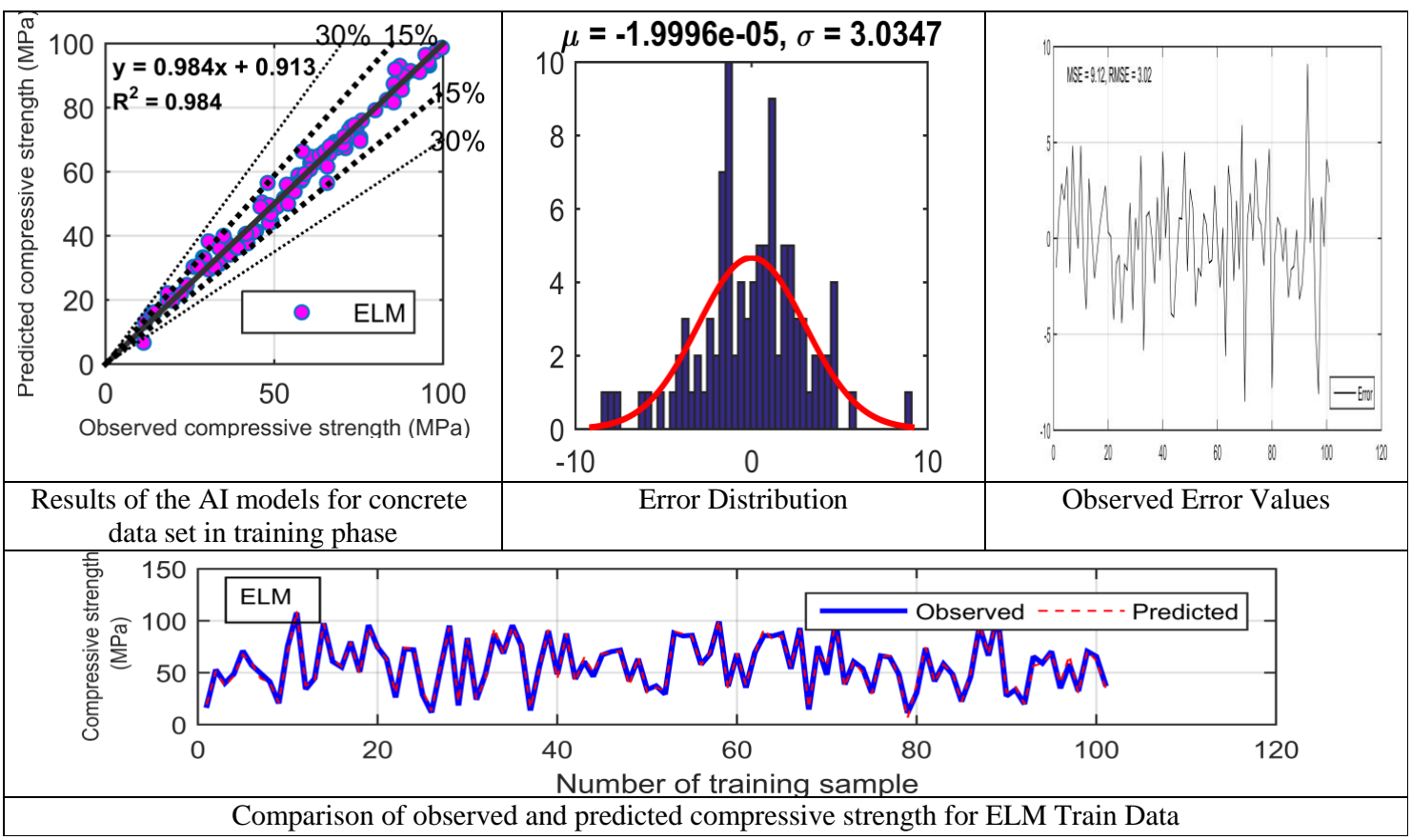

Fig. 8: ELM model training outputs.

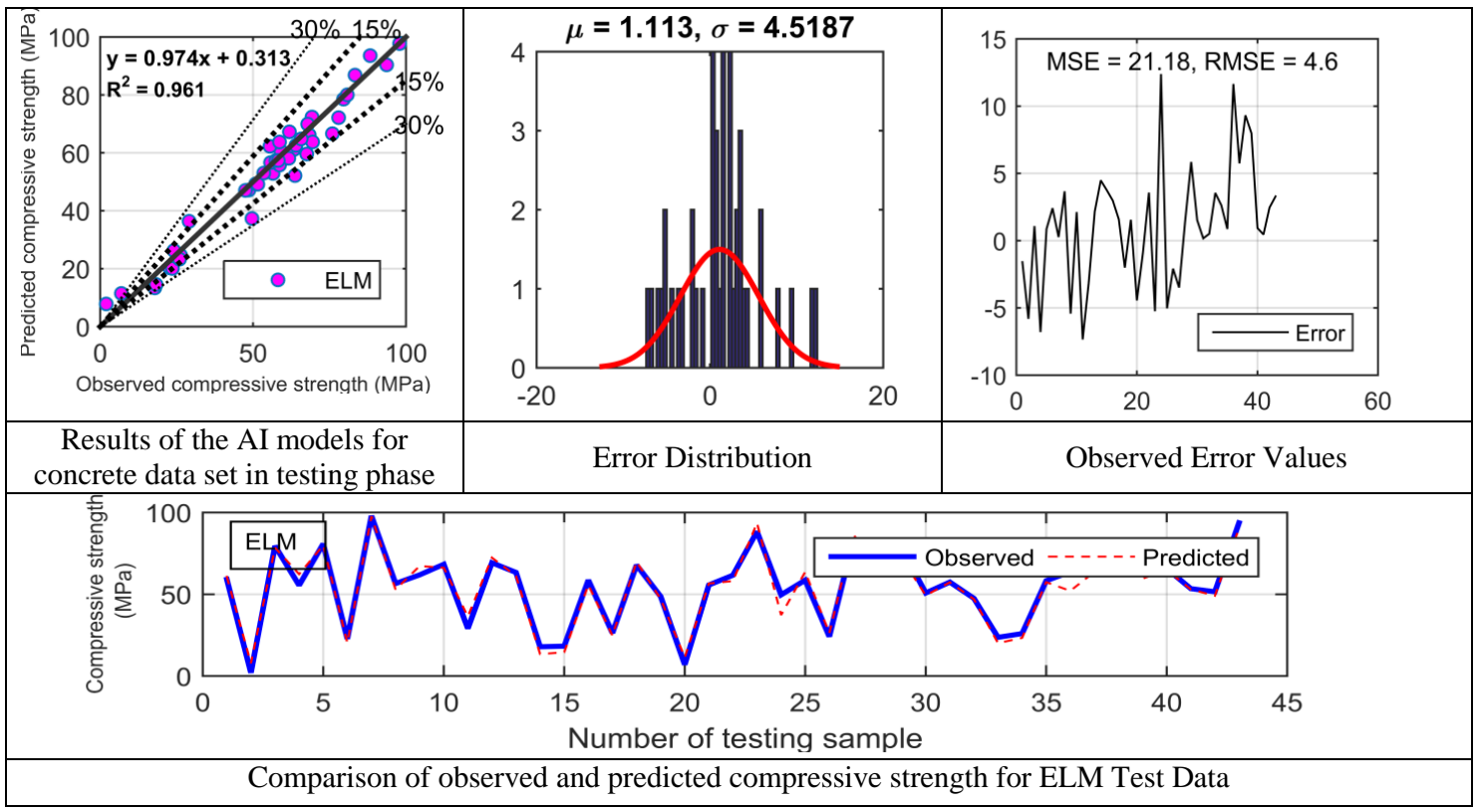

Fig. 9: ELM model testing outputs.

are compared and since the value of ANN is near to 1 , then the best performance metrics belong to $\mathrm{ANN}$ in approximating the CS of concrete in adding silica fume and fly ash. As a result, ANN represented superior performance in this study. 
Tab. 8: Comparing the training phase results between ANN model and ELM model.

\begin{tabular}{|l|l|l|l|l|l|l|}
\hline \multicolumn{7}{|c|}{ Training phase } \\
\hline AI Models & $R^{2}$ & $R M S E$ & $M A E$ & $R R M S E$ & $R M A$ & $W I$ \\
\hline ANN & 0.9959 & 1.5345 & 1.1377 & 2.6523 & 1.9663 & 0.9990 \\
\hline ELM & 0.9842 & 3.0196 & 2.3337 & 5.2191 & 4.0335 & 0.9960 \\
\hline
\end{tabular}

Tab. 9: Comparing the testing phase results between ANN model and ELM model.

\begin{tabular}{|l|l|l|l|l|l|l|}
\hline \multicolumn{7}{|c|}{ Testing phase } \\
\hline AI Models & $R^{2}$ & $R M S E$ & $M A E$ & $R R M S E$ & $R M A$ & $W I$ \\
\hline ANN & 0.9905 & 2.2086 & 1.7252 & 4.1092 & 3.2098 & 0.9976 \\
\hline ELM & 0.9616 & 4.6025 & 3.5945 & 8.3895 & 6.5521 & 0.9896 \\
\hline
\end{tabular}

\section{Conclusion}

Predicting the CS of concrete is an important challenge in construction industry. In reality, calculating the concrete strength in traditional testing method takes time, cost, error in percentages and lack of accuracy. Accordingly, the CS of concrete has been analyzed while adding silica fume and fly ash through AI algorithms as ANN and ELM [13]. Collecting data set was from the appraisal of long-term influences of silica fume and fly ash on the CS of concrete by NNs including 144 various concrete mixtures. Water cement $(\mathrm{w} / \mathrm{c})$ ratio was differed during the test comprising the high and low FA content and with(out) extra small SF content. The concrete of samples was cured for 3, 7, 28, 56 and 180 days. To achieve the best performance of the models, a trial and error method has been performed to gain the optimum values of free parameters. Due to inadequate outcome in the $1^{\text {th }}$ layer with 6 neurons in $\mathrm{ANN}$, the $2^{\text {nd }}$ layer was used comprising 4 neurons (second layer), then the best performance of ANN is observed in the second layer with 4 neurons. Alternatively, due to SLFNN architecture of ELM, there was only one hidden layer in ELM and the best architecture was seen with 67 neurons as the best ELM performance. After analyzing the RMSE and $\mathrm{R}^{2}(R S Q R)$ values of both models derived from the training and testing phases of the two models, it resulted that ANN could remarkably show better performance than ELM. Since the best $R M S E$ should be equal or near to 0 , then the RMSE of ANN (2.2086) is close to 0, however, the RMSE of ELM (4.6025) is far from
0 . As a result, ANN could perform better than ELM in estimating and predicting the CS of concrete while adding silica fume and fly ash. On the other hands, by comparing the two values of $R^{2}(R S Q R)$ in ANN and ELM, the $R^{2}$ value of ANN (0.9905) and ELM (0.9616) should be equal or close to 1 (as the best $R^{2}$ value) in order to be nominated as an accurate model for predicting the CS of concrete in this study. Therefore, while the $R^{2}$ value of ELM is far from 1 , the $R^{2}$ value of ANN is close to 1 , then ANN is accounted as the best model in predicting and estimating the CS of concrete while adding silica fume and fly ash. Consequently, ANN was superior to ELM in accurately approximating the CS of concrete. Also, it was found that fly ash had less contribution to the compressive strength of concrete at early ages, however, had great contribution at later ages. It can also be concluded that the enhancement effect of low content of SF on compressive strength was not significant. On the other hand, adding fly ash has decreased the early compressive strength, but raised the compressive strength in the long-term. Adding silica fume raises the strength in short term, but decreases the strength in long term. Comparing the results of this study with the original one, going through the $R^{2}$ value of the original one (0.9990) in testing phase and the $R^{2}$ value of this study is 0.9905 in testing in ANN model. Therefore, both studies could represent the same accuracy with the least differential percentages. 


\section{References}

[1] Yazdani, N., Filsaime, M., \& Islam, S. (2008). Accelerated curing of silica-fume concrete. Journal of materials in civil engineering, 20(8), 521-529.

[2] Jain, A., \& Pawade, P. (2015). Characteristics of silica fume concrete. International Journal of Computer Applications, 975, 8887.

[3] Demirboğa, R., Örüng, İ., \& Gül, R. (2001). Effects of expanded perlite aggregate and mineral admixtures on the compressive strength of low-density concretes. Cement and Concrete Research, 31(11), 1627-1632.

[4] Bilodeau, A., \& Malhotra, V.M. (2000). High-volume fly ash system: concrete solution for sustainable development. Materials Journal, 97(1), 41-48.

[5] Khedr, S.A., \& Abou-Zeid, M.N. (1994). Characteristics of silica-fume concrete. Journal of Materials in Civil Engineering, $6(3), 357-375$.

[6] Atiş, C., et al. (2005). Influence of dry and wet curing conditions on compressive strength of silica fume concrete. Building and environment, 40(12), 1678-1683.

[7] Toutanji, H.A., \& Bayasi, Z. (1999). Effect of curing procedures on properties of silica fume concrete. Cement and Concrete research, 29(4), 497-501.

[8] Khatri, R., Sirivivatnanon, V., \& Gross, W. (1995). Effect of different supplementary cementitious materials on mechanical properties of high performance concrete. Cement and Concrete Research, 25(1), 209-220.

[9] Sabir, B. (1995). High-strength condensed silica fume concrete. Magazine of Concrete Research, 47(172), 219-226.

[10] Khatri, R., Sirivivatnanon, V., \& Kin yu, L. (1997). Effect of curing on water permeability of concretes prepared with normal Portland cement and with slag and silica fume. Magazine of concrete research, 49(180), 167-172.
[11] Iravani, S. (1996). Mechanical properties of high-performance concrete. Materials Journal, 93(5), 416-426.

[12] Detwiler, R.J., \& Mehta, P.K. (1989). Chemical and physical effects of silica fume on the mechanical behavior of concrete. Materials Journal, 86(6), 609-614.

[13] Mazloom, M., Ramezanianpour, A., \& Brooks, J. (2004). Effect of silica fume on mechanical properties of high-strength concrete. Cement and Concrete Composites, $26(4), 347-357$.

[14] Xie, J., Elwi, A., \& MacGregor, J. (1995). Mechanical properties of three highstrength concretes containing silica fume. Materials Journal, 92(2), 135-145.

[15] Cetin, A., \& Carrasquillo, R.L. (1998). High-performance concrete: influence of coarse aggregates on mechanical properties. Materials Journal, 95(3), 252-261.

[16] Goldman, A., \& Bentur, A. (1993). The influence of microfillers on enhancement of concrete strength. Cement and concrete research, 23(4), 962-972.

[17] Hooton, R. (1993). Influence of silica fume replacement of cement on physical properties and resistance to sulfate attack, freezing and thawing, and alkali-silica reactivity. Materials Journal, 90(2), 143-151.

[18] Zhou, F., Barr, B., \& Lydon, F. (1995). Fracture properties of high strength concrete with varying silica fume content and aggregates. Cement and concrete research, $25(3), 543-552$.

[19] Yogendran, V., et al. (1987). Silica fume in high-strength concrete. Materials Journal, $84(2), 124-129$.

[20] Elahi, A., et al. (2010). Mechanical and durability properties of high performance concretes containing supplementary cementitious materials. Construction and Building Materials, 24 (3), 292-299.

[21] Malhotra, V., \& Mehta, P. (1996). Puzzolanic and cementitious materials, Advances in Concrete Technology, Edit. Gordon and Brach Publishers. 
[22] Dotto, J., et al. (2004). Influence of silica fume addition on concretes physical properties and on corrosion behaviour of reinforcement bars. cement and concrete composites, 26(1), 31-39.

[23] Behnood, A., \& Ziari, H. (2008). Effects of silica fume addition and water to cement ratio on the properties of high-strength concrete after exposure to high temperatures. Cement and Concrete Composites, 30(2), 106-112.

[24] Türker, F., et al. (1997). Effects of magnesium sulfate concentration on the sulfate resistance of mortars with and without silica fume. Cement and concrete research, 27(2), 205-214.

[25] Aköz, F., et al. (1995). Effects of sodium sulfate concentration on the sulfate resistance of mortars with and without silica fume. Cement and concrete research, 25 (6), 1360-1368.

[26] Aköz, F., et al. (1999). Effects of raised temperature of sulfate solutions on the sulfate resistance of mortars with and without silica fume. Cement and Concrete Research, $29(4), 537-544$.

[27] Al-Khaja, W.A., (1994). Strength and time-dependent deformations of silica fume concrete for use in Bahrain. Construction and Building Materials, 8(3), 169-172.

[28] Alexander, M., \& Magee, B. (1999). Durability performance of concrete containing condensed silica fume. Cement and concrete research, 29(6), 917-922.

[29] Poon, C.-S., Kou, S., \& Lam, L. (2006). Compressive strength, chloride diffusivity and pore structure of high performance metakaolin and silica fume concrete. Construction and building materials, 20(10), 858-865.

[30] Köksal, F., et al. (2008). Combined effect of silica fume and steel fiber on the mechanical properties of high strength concretes. Construction and building materials, 22(8), 1874-1880.
[31] Rafieizonooz, M., et al. (2016). Investigation of coal bottom ash and fly ash in concrete as replacement for sand and cement. Construction and Building Materials, 116, $15-24$

[32] Thomas, M. (2007). Optimizing the use of fly ash in concrete. Vol. 5420: Portland Cement Association Skokie, IL.

[33] Naik, T.R., \& Singh, S. (1993). Fly ash generation and utilization. Recent Trend in Fly Ash Utilization.

[34] Abubakar, A.U., \& Baharudin, K.S. (2012). Potential use of Malaysian thermal power plants coal bottom ash in construction. International Journal of Sustainable Construction Engineering and Technology, 3(2), 25-37.

[35] Hsu, S., Chi, M., \& Huang, R. (2018). Effect of fineness and replacement ratio of ground fly ash on properties of blended cement mortar. Construction and Building Materials, 176, 250-258.

[36] Chindaprasirt, P., Jaturapitakkul, C., \& Sinsiri, T. (2007). Effect of fly ash fineness on microstructure of blended cement paste. Construction and Building Materials, 21(7), 1534-1541.

[37] Yao, Z., et al. (2015). A comprehensive review on the applications of coal fly ash. Earth-Science Reviews, 141, 105-121.

[38] Naik, T.R., \& Singh, S.S. (1998). Fly ash generation and utilization-an overview. Published in the book titled" Recent Trend in Fly Ash Utilization", Ministry of Environment and Forests, Government of India.

[39] Pandey, S. (2014). Coal fly ash: Some aspects of characterization and environmental impacts. Journal of Environmental Science, Computer Science and Engineering \& Technology, 3, 921-937.

[40] Khankhaje, E., et al. (2016). On blended cement and geopolymer concretes containing palm oil fuel ash. Materials \& Design, 89, 385-398. 
[41] Openshaw, S. (1992). Utilization of coal fly ash. Master's thesis, Florida Univ., Gainesville, FL (United States).

[42] Ahmaruzzaman, M. (2010). A review on the utilization of fly ash. Progress in energy and combustion science, 36(3), 327-363.

[43] Kearsley, E., \& Wainwright, P. (2001). The effect of high fly ash content on the compressive strength of foamed concrete. $\mathrm{Ce}$ ment and concrete research, 31 (1), 105-112.

[44] Behnood, A., \& Golafshani, E.M. (2018). Predicting the compressive strength of silica fume concrete using hybrid artificial neural network with multi-objective grey wolves. Journal of cleaner production, 202, 54-64.

[45] Pala, M., et al. (2007). Appraisal of longterm effects of fly ash and silica fume on compressive strength of concrete by neural networks. Construction and Building Materials, 21 (2), 384-394.

[46] Gamage, N., et al. (2011). Overview of different types of fly ash and their use as a building and construction material.

[47] Maher, M., \& Balaguru, P. (1993). Properties of flowable high-volume fly ash-cement composite. Journal of materials in civil engineering, 5(2), 212-225.

[48] Mitash, N. (2007). Utility bonanza from dust. Envist Newsletter, 2(6), 575-579.

[49] Huang, R., Chang, J., \& Yeih, W. (1995). Engineering properties and application of cement-based fly ash blocks. Journal of Marine Science and Technology, 3(1).

[50] Marto, A., et al. (2010). Engineering characteristics of Tanjung Bin coal ash. Electronic Journal of Geotechnical Engineering, 15, 1117-1129.

[51] Golafshani, E.M., \& Behnood, A. (2018). Application of soft computing methods for predicting the elastic modulus of recycled aggregate concrete. Journal of cleaner production, 176, 1163-1176.
[52] Golafshani, E.M., \& A.Behnood, (2018). Automatic regression methods for formulation of elastic modulus of recycled aggregate concrete. Applied Soft Computing, 64, 377-400.

[53] Erdal, H.I. (2013). Two-level and hybrid ensembles of decision trees for high performance concrete compressive strength prediction. Engineering Applications of Artificial Intelligence, 26(7), 1689-1697.

[54] Chiew, F.H., et al. (2017). A Fuzzy Adaptive Resonance Theory-Based Model for Mix Proportion Estimation of HighPerformance Concrete. Computer-Aided Civil and Infrastructure Engineering, 32(9), 772-786.

[55] Behnood, A., et al. (2017). Prediction of the compressive strength of normal and highperformance concretes using M5P model tree algorithm. Construction and Building Materials, 142, 199-207.

[56] Behnood, A., Olek, J., \& Glinicki, M.A. (2015). Predicting modulus elasticity of recycled aggregate concrete using M5' model tree algorithm. Construction and Building Materials, 94, 137-147.

[57] Behnood, A., Verian, K.P., \& Gharehveran, M.M. (2015). Evaluation of the splitting tensile strength in plain and steel fiberreinforced concrete based on the compressive strength. Construction and Building Materials, 98, 519-529.

[58] Cheng, M.-Y., Firdausi, P.M., \& Prayogo, D. (2014). High-performance concrete compressive strength prediction using Genetic Weighted Pyramid Operation Tree (GWPOT). Engineering Applications of Artificial Intelligence, 29, 104-113.

[59] Golafshani, E.M., \& Ashour, A. (2016). Prediction of self-compacting concrete elastic modulus using two symbolic regression techniques. Automation in Construction, 64, 7-19.

[60] Uddin, M.T., et al. (2017). Effects of maximum size of brick aggregate on properties 
of concrete. Construction and Building $\mathrm{Ma-}$ terials, 134, 713-726.

[61] Nikoo, M., Moghadam, F.T., \& Sadowski, Ł. (2015). Prediction of concrete compressive strength by evolutionary artificial neural networks. Advances in Materials Science and Engineering.

[62] Atici, U. (2011). Prediction of the strength of mineral admixture concrete using multivariable regression analysis and an artificial neural network. Expert Systems with applications, 38(8), 9609-9618.

[63] Prasad, B.R., Eskandari, H., \& Reddy, B.V. (2009). Prediction of compressive strength of SCC and HPC with high volume fly ash using ANN. Construction and Building Materials, 23(1), 117-128.

[64] Yeh, I.-C., \& Lien, L.-C. (2009). Knowledge discovery of concrete material using genetic operation trees. Expert Systems with Applications, 36(3), 5807-5812.

[65] Chou, J.-S., et al. (2011). Optimizing the prediction accuracy of concrete compressive strength based on a comparison of datamining techniques. Journal of Computing in Civil Engineering, 25(3), 242-253.

[66] Deepa, C., SathiyaKumari, K., \& Sudha, V.P. (2010). Prediction of the compressive strength of high performance concrete mix using tree based modeling. International Journal of Computer Applications, 6(5), 18-24.

[67] Bui, D.-K., et al. (2018). A modified firefly algorithm-artificial neural network expert system for predicting compressive and tensile strength of high-performance concrete. Construction and Building Materials, 180, 320-333.

[68] Topcu, I.B., \& Sarıdemir, M. (2008). Prediction of compressive strength of concrete containing fly ash using artificial neural networks and fuzzy logic. Computational $\mathrm{Ma}$ terials Science, 41(3), 305-311.

[69] Zarandi, M.F., et al. (2008). Fuzzy polynomial neural networks for approximation of the compressive strength of concrete. $A p$ plied Soft Computing, 8(1), 488-498.

[70] Bilim, C., et al. (2009). Predicting the compressive strength of ground granulated blast furnace slag concrete using artificial neural network. Advances in Engineering Software, 40(5), 334-340.

[71] Naderpour, H., Rafiean, A.H., \& Fakharian, P. (2018). Compressive strength prediction of environmentally friendly concrete using artificial neural networks. Journal of Building Engineering, 16, 213-219.

[72] Velay-Lizancos, M., et al. (2017). Analytical and genetic programming model of compressive strength of eco concretes by NDT according to curing temperature. Construction and Building Materials, 144, 195-206.

[73] Asteris, P.G., \& Mokos, V.G. (2019). Concrete compressive strength using artificial neural networks. Neural Computing and Applications, 1-20.

[74] Al-Shamiri, A.K., et al. (2019). Modeling the compressive strength of high-strength concrete: An extreme learning approach. Construction and Building Materials, 208, 204-219.

[75] Yaseen, Z.M., et al. (2018). Predicting compressive strength of lightweight foamed concrete using extreme learning machine model. Advances in Engineering Software, 115, 112-125.

[76] Akande, K.O., et al. (2014). Performance comparison of SVM and ANN in predicting compressive strength of concrete. IOSR Journal of Computer Engineering, 16(5), 88-94.

[77] Chithra, S., et al. (2016). A comparative study on the compressive strength prediction models for High Performance Concrete containing nano silica and copper slag using regression analysis and Artificial Neural Networks. Construction and Building Materials, 114, 528-535.

[78] Sarıdemir, M. (2010). Genetic programming approach for prediction of compressive strength of concretes containing rice 
husk ash. Construction and Building $M a-$ terials, $24(10), 1911-1919$.

[79] Öztaş, A., et al. (2006). Predicting the compressive strength and slump of high strength concrete using neural network. Construction and building materials, 20(9), 769-775.

[80] Jahed Armaghani, D., et al. (2017). Uniaxial compressive strength prediction through a new technique based on gene expression programming. Neural Computing and Applications, 30(11), 3523-3532.

[81] Abdelkader, B., El-Hadj, K., \& Karim, E. (2010). Efficiency of granulated blast furnace slag replacement of cement according to the equivalent binder concept. Cement and Concrete Composites, 32(3), 226-231.

[82] Faradonbeh, R.S., et al. (2018). Development of GP and GEP models to estimate an environmental issue induced by blasting operation. Environ Monit Assess, 190(6), 351.

[83] Saad, S., \& Malik, H. (2018). Gene expression programming (GEP) based intelligent model for high performance concrete comprehensive strength analysis. Journal of Intelligent \& Fuzzy Systems, 1-16.

[84] Priddy, K.L., \& Keller, P.E. (2005). Artificial neural networks: an introduction. SPIE press.

[85] Amiri, M., et al. (2016). A new combination of artificial neural network and K-nearest neighbors models to predict blast-induced ground vibration and air-overpressure. Engineering with Computers, 32(4), 631-644.

[86] Salas, D.A., et al. (2016). Environmental impacts, life cycle assessment and potential improvement measures for cement production: a literature review. Journal of Cleaner Production, 113, 114-122.

[87] Moosazadeh, S., et al. (2018). Prediction of building damage induced by tunnelling through an optimized artificial neural network. Engineering with Computers, 1-13.
[88] Moré, J.J. (1978). The LevenbergMarquardt algorithm: implementation and theory, in Numerical analysis. Springer, 105-116.

[89] Li, J., et al. (2012). Brief introduction of back propagation (BP) neural network algorithm and its improvement, in Advances in computer science and information engineering. Springer, 553-558.

[90] Huang, G.-B., Zhu, Q.-Y., \& Siew, C.-K. (2006). Extreme learning machine: theory and applications. Neurocomputing, $70(1)$, 489-501.

[91] Huang, G.-B., (2003). Learning capability and storage capacity of two-hidden-layer feedforward networks. IEEE Transactions on Neural Networks, 14(2), 274-281.

[92] Haji Agha Mohammad Zarbaf, S.E., et al. (2017). Stay Cable Tension Estimation of Cable-Stayed Bridges Using Genetic Algorithm and Particle Swarm Optimization. Journal of Bridge Engineering, 22(10), 05017008.

[93] Shariati, M., et al. (2019). Moment-rotation estimation of steel rack connection using extreme learning machine. Steel and Composite Structures, 31(5), 427-435.

[94] Huang, G.-B., Zhu, Q.-Y., \& Siew, C.-K. (2006). Extreme learning machine: theory and applications. Neurocomputing, $70(1-3)$, 489-501.

[95] El Debs, A.L.H., et al. (2005). Optimization of cross section of reinforced concrete beam using experimental design.

\section{About Authors}

Mahdi SHARIATI obtained his Ph.D. degree from the University of Malaya in 2013. Now, Mahdi is a research fellow at the Institute of Research and Development, Duy Tan University, Viet Nam. He has published over 100 ISI papers in prestigious journals. Also, he has two patents about novel C-shaped shear connectors 
in steel-concrete composite structures and Enhanced steel-concrete composite floor systems using V-shaped angle shear connectors. The research interests of Mahdi are Shear Connector, Concrete Technology, Artificial Intelligence, Optimization Algorithms and Building Information Modelling. Currently, he is serving as the Editor of Journal of Advanced Engineering and Computation (JAEC). Besides, he is the Reviewer of over 30 well-known journals.

Danial Jahed ARMAGHANI is currently working as a senior lecturer in the Faculty of Engineering, University of Malaya, Malaysia. He received his postdoc from Amirkabir University of Technology, Tehran, Iran and his Ph.D. degree, in Civil Geotechnics, from Universiti Teknologi Malaysia, Malaysia. His area of research is tunnelling, rock mechanics, piling technology, blasting environmental issues, applying artificial intelligence, and optimization algorithms in civil-geotechnics. Dr. Danial published more than 150 papers in well-established ISI and Scopus journals, national, and international conferences. Dr. Danial is also a recognized reviewer in the area of rock mechanics and geotechnical engineering.

Manoj KHANDELWAL is a Program Coordinator of mining engineering at Federation University and is an Australian Endeavour Fellow and also a member of the Australasian Institute of Mining and Metallurgy, Society for Mining, Metallurgy and Exploration, USA, and Mining Engineers Association of India. Dr Khandelwal has more than a decade of research and academic teaching experience in Australia and India. Dr Khandelwal has been recognized as a leading expert in 'Mining Geomechanics' and 'Rock Blasting'. So far, Dr Khandelwal has published more than 125 research papers in different reputed journals with high impact factors and reputable conference proceedings. $\mathrm{He}$ is also the author of a book. He has successfully completed several research and consultancy research projects in his area of interest. He has been awarded a number of prestigious national and international awards. Dr Khandelwal is a member of the editorial board of several international journals published from various continents.

Jian ZHOU received the Ph.D. degree from the School of Resources and Safety Engineering, Central South University, Changsha, China, in 2015. From 2013 to 2014, he was a Visitor scholar with the McGill University, Montreal, Canada. His current research interests in prediction and control of mining and geotechnical engineering hazards using machine learning methods, including rockburst in deep hardrock mining and high-stress conditions, pillar and stope stability analysis, blast vibration, slope stability analysis. He is currently an Associate Professor with the School of Resource and Safety Engineering, Central South University. He is a member of ISRM and invited to serve as the Editor or Editorial Board Member of International Journal of Mining Science and Technology, Advances in Civil Engineering, Applied Sciences, Metaheuristic Computing and Applications. He has authored over 100 papers published in related international journals. $\mathrm{He}$ has served as a Reviewer of over 40 journals.

Majid KHORAMI is a Ph.D candidate in Politecnic University of Valencia-Spain. Currently, he is working as an associate professor in the Faculty of Architecture and Urbanism, UTE University in Ecuador with more than a decade of research and academic teaching experience. His area of research is Ultra-High Performance Fibre Concrete (UHPFRC), applying artificial intelligence, concrete technology and sustainable construction. He has authored/co-authored over 50 papers published in well-known international journals and reviewer over 5 journals. 


\section{Appendix}

\section{Details of mix proportions and their CS variables}

Tab. 10: Details of mix proportions and their CS variables

\begin{tabular}{|c|c|c|c|c|c|c|c|c|c|}
\hline S. number & $\begin{array}{l}\text { FA } \\
(\%)\end{array}$ & $\begin{array}{l}\text { SF } \\
(\%)\end{array}$ & $\begin{array}{l}\text { TCM } \\
\left(\mathrm{kg} / \mathrm{m}^{3}\right)\end{array}$ & $\begin{array}{l}\text { ssa } \\
\left(\mathrm{kg} / \mathrm{m}^{3}\right)\end{array}$ & $\begin{array}{l}\text { ca } \\
\left(\mathrm{kg} / \mathrm{m}^{3}\right)\end{array}$ & $\begin{array}{l}\mathrm{W} \\
\left(\mathrm{lt} / \mathrm{m}^{3}\right)\end{array}$ & $\begin{array}{l}\text { HRWRA } \\
\left(\mathrm{lt} / \mathrm{m}^{3}\right)\end{array}$ & $\begin{array}{l}\text { Age } \\
\text { (days) }\end{array}$ & $\begin{array}{l}\text { fc } \\
(\mathrm{MPa})\end{array}$ \\
\hline 1 & 0 & 0 & 500 & 724 & 1086 & 150 & 7.5 & 3 & 64.9 \\
\hline 2 & 0 & 0 & 500 & 724 & 1086 & 150 & 7.5 & 7 & 75.5 \\
\hline 3 & 0 & 0 & 500 & 724 & 1086 & 150 & 7.5 & 28 & 86.8 \\
\hline 4 & 0 & 0 & 500 & 724 & 1086 & 150 & 7.5 & 56 & 87.2 \\
\hline 5 & 0 & 0 & 500 & 724 & 1086 & 150 & 7.5 & 90 & 95.7 \\
\hline 6 & 0 & 0 & 500 & 724 & 1086 & 150 & 7.5 & 180 & 97.7 \\
\hline 7 & 15 & 0 & 500 & 700 & 1086 & 150 & 7.5 & 3 & 52.1 \\
\hline 8 & 15 & 0 & 500 & 700 & 1086 & 150 & 7.5 & 7 & 66.4 \\
\hline 9 & 15 & 0 & 500 & 700 & 1086 & 150 & 7.5 & 28 & 86 \\
\hline 10 & 15 & 0 & 500 & 700 & 1086 & 150 & 7.5 & 56 & 94.8 \\
\hline 11 & 15 & 0 & 500 & 700 & 1086 & 150 & 7.5 & 90 & 99.6 \\
\hline 12 & 15 & 0 & 500 & 700 & 1086 & 150 & 7.5 & 180 & 106.3 \\
\hline 13 & 25 & 0 & 500 & 683 & 1086 & 150 & 9.25 & 3 & 48 \\
\hline 14 & 25 & 0 & 500 & 683 & 1086 & 150 & 9.25 & 7 & 65.7 \\
\hline 15 & 25 & 0 & 500 & 683 & 1086 & 150 & 9.25 & 28 & 85.4 \\
\hline 16 & 25 & 0 & 500 & 683 & 1086 & 150 & 9.25 & 56 & 90.4 \\
\hline 17 & 25 & 0 & 500 & 683 & 1086 & 150 & 9.25 & 90 & 95.4 \\
\hline 18 & 25 & 0 & 500 & 683 & 1086 & 150 & 9.25 & 180 & 107.8 \\
\hline 19 & 45 & 0 & 500 & 650 & 1086 & 150 & 10.5 & 3 & 34.1 \\
\hline 20 & 45 & 0 & 500 & 650 & 1086 & 150 & 10.5 & 7 & 49.2 \\
\hline 21 & 45 & 0 & 500 & 650 & 1086 & 150 & 10.5 & 28 & 71.8 \\
\hline 22 & 45 & 0 & 500 & 650 & 1086 & 150 & 10.5 & 56 & 85.4 \\
\hline 23 & 45 & 0 & 500 & 650 & 1086 & 150 & 10.5 & 90 & 87.7 \\
\hline 24 & 45 & 0 & 500 & 650 & 1086 & 150 & 10.5 & 180 & 97.7 \\
\hline 25 & 55 & 0 & 500 & 634 & 1086 & 150 & 13 & 3 & 22.3 \\
\hline 26 & 55 & 0 & 500 & 634 & 1086 & 150 & 13 & 7 & 36.4 \\
\hline 27 & 55 & 0 & 500 & 634 & 1086 & 150 & 13 & 28 & 57.4 \\
\hline 28 & 55 & 0 & 500 & 634 & 1086 & 150 & 13 & 56 & 66.6 \\
\hline 29 & 55 & 0 & 500 & 634 & 1086 & 150 & 13 & 90 & 72.8 \\
\hline 30 & 55 & 0 & 500 & 634 & 1086 & 150 & 13 & 180 & 79.9 \\
\hline 31 & 0 & 5 & 500 & 719 & 1086 & 150 & 8 & 3 & 58.3 \\
\hline 32 & 0 & 5 & 500 & 719 & 1086 & 150 & 8 & 7 & 75.5 \\
\hline 33 & 0 & 5 & 500 & 719 & 1086 & 150 & 8 & 28 & 87.8 \\
\hline 34 & 0 & 5 & 500 & 719 & 1086 & 150 & 8 & 56 & 93.1 \\
\hline 35 & 0 & 5 & 500 & 719 & 1086 & 150 & 8 & 90 & 93.6 \\
\hline 36 & 0 & 5 & 500 & 719 & 1086 & 150 & 8 & 180 & 99.3 \\
\hline 37 & 20 & 5 & 500 & 686 & 1086 & 150 & 9.25 & 3 & 46.3 \\
\hline 38 & 20 & 5 & 500 & 686 & 1086 & 150 & 9.25 & 7 & 65.6 \\
\hline 39 & 20 & 5 & 500 & 686 & 1086 & 150 & 9.25 & 28 & 78.5 \\
\hline 40 & 20 & 5 & 500 & 686 & 1086 & 150 & 9.25 & 56 & 85.8 \\
\hline
\end{tabular}


(continued from previous page)

\begin{tabular}{|c|c|c|c|c|c|c|c|c|c|}
\hline S. number & $\begin{array}{l}\text { FA } \\
(\%)\end{array}$ & $\begin{array}{l}\text { SF } \\
(\%)\end{array}$ & $\begin{array}{l}\text { TCM } \\
\left(\mathrm{kg} / \mathrm{m}^{3}\right)\end{array}$ & $\begin{array}{l}\mathrm{ssa} \\
\left(\mathrm{kg} / \mathrm{m}^{3}\right)\end{array}$ & $\begin{array}{l}\mathrm{ca} \\
\left(\mathrm{kg} / \mathrm{m}^{3}\right)\end{array}$ & $\begin{array}{l}\text { W } \\
\left(\mathrm{lt} / \mathrm{m}^{3}\right)\end{array}$ & $\begin{array}{l}\text { HRWRA } \\
\left(\mathrm{lt} / \mathrm{m}^{3}\right)\end{array}$ & $\begin{array}{l}\text { Age } \\
\text { (days) }\end{array}$ & $\begin{array}{l}\text { fc } \\
(\mathrm{MPa})\end{array}$ \\
\hline 41 & 20 & 5 & 500 & 686 & 1086 & 150 & 9.25 & 90 & 90.3 \\
\hline 42 & 20 & 5 & 500 & 686 & 1086 & 150 & 9.25 & 180 & 95.9 \\
\hline 43 & 40 & 5 & 500 & 654 & 1086 & 150 & 11 & 3 & 30.5 \\
\hline 44 & 40 & 5 & 500 & 654 & 1086 & 150 & 11 & 7 & 48.6 \\
\hline 45 & 40 & 5 & 500 & 654 & 1086 & 150 & 11 & 28 & 71.1 \\
\hline 46 & 40 & 5 & 500 & 654 & 1086 & 150 & 11 & 56 & 80 \\
\hline 47 & 40 & 5 & 500 & 654 & 1086 & 150 & 11 & 90 & 83.4 \\
\hline 48 & 40 & 5 & 500 & 654 & 1086 & 150 & 11 & 180 & 88.3 \\
\hline 49 & 0 & 0 & 400 & 710 & 1157 & 160 & 4 & 3 & 35 \\
\hline 50 & 0 & 0 & 400 & 710 & 1157 & 160 & 4 & 7 & 48.4 \\
\hline 51 & 0 & 0 & 400 & 710 & 1157 & 160 & 4 & 28 & 60.7 \\
\hline 52 & 0 & 0 & 400 & 710 & 1157 & 160 & 4 & 56 & 67.1 \\
\hline 53 & 0 & 0 & 400 & 710 & 1157 & 160 & 4 & 90 & 70.5 \\
\hline 54 & 0 & 0 & 400 & 710 & 1157 & 160 & 4 & 180 & 70.6 \\
\hline 55 & 15 & 0 & 400 & 690 & 1157 & 160 & 4.4 & 3 & 29.3 \\
\hline 56 & 15 & 0 & 400 & 690 & 1157 & 160 & 4.4 & 7 & 39.9 \\
\hline 57 & 15 & 0 & 400 & 690 & 1157 & 160 & 4.4 & 28 & 56 \\
\hline 58 & 15 & 0 & 400 & 690 & 1157 & 160 & 4.4 & 56 & 63.4 \\
\hline 59 & 15 & 0 & 400 & 690 & 1157 & 160 & 4.4 & 90 & 68.5 \\
\hline 60 & 15 & 0 & 400 & 690 & 1157 & 160 & 4.4 & 180 & 72.1 \\
\hline 61 & 25 & 0 & 400 & 660 & 1157 & 160 & 4.8 & 3 & 24.7 \\
\hline 62 & 25 & 0 & 400 & 660 & 1157 & 160 & 4.8 & 7 & 33.7 \\
\hline 63 & 25 & 0 & 400 & 660 & 1157 & 160 & 4.8 & 28 & 49.3 \\
\hline 64 & 25 & 0 & 400 & 660 & 1157 & 160 & 4.8 & 56 & 60.8 \\
\hline 65 & 25 & 0 & 400 & 660 & 1157 & 160 & 4.8 & 90 & 66.2 \\
\hline 66 & 25 & 0 & 400 & 660 & 1157 & 160 & 4.8 & 180 & 70.2 \\
\hline 67 & 45 & 0 & 400 & 634 & 1157 & 160 & 5.2 & 3 & 14.5 \\
\hline 68 & 45 & 0 & 400 & 634 & 1157 & 160 & 5.2 & 7 & 20.3 \\
\hline 69 & 45 & 0 & 400 & 634 & 1157 & 160 & 5.2 & 28 & 43.9 \\
\hline 70 & 45 & 0 & 400 & 634 & 1157 & 160 & 5.2 & 56 & 54.1 \\
\hline 71 & 45 & 0 & 400 & 634 & 1157 & 160 & 5.2 & 90 & 61.2 \\
\hline 72 & 45 & 0 & 400 & 634 & 1157 & 160 & 5.2 & 180 & 63.7 \\
\hline 73 & 55 & 0 & 400 & 621 & 1157 & 160 & 5.5 & 3 & 13.6 \\
\hline 74 & 55 & 0 & 400 & 621 & 1157 & 160 & 5.5 & 7 & 19.8 \\
\hline 75 & 55 & 0 & 400 & 621 & 1157 & 160 & 5.5 & 28 & 37.3 \\
\hline 76 & 55 & 0 & 400 & 621 & 1157 & 160 & 5.5 & 56 & 47.1 \\
\hline 77 & 55 & 0 & 400 & 621 & 1157 & 160 & 5.5 & 90 & 52.9 \\
\hline 78 & 55 & 0 & 400 & 621 & 1157 & 160 & 5.5 & 180 & 63.2 \\
\hline 79 & 0 & 5 & 400 & 688 & 1157 & 160 & 5.5 & 3 & 37.3 \\
\hline 80 & 0 & 5 & 400 & 688 & 1157 & 160 & 5.5 & 7 & 53 \\
\hline 81 & 0 & 5 & 400 & 688 & 1157 & 160 & 5.5 & 28 & 69.4 \\
\hline 82 & 0 & 5 & 400 & 688 & 1157 & 160 & 5.5 & 56 & 72.1 \\
\hline 83 & 0 & 5 & 400 & 688 & 1157 & 160 & 5.5 & 90 & 73.7 \\
\hline 84 & 0 & 5 & 400 & 688 & 1157 & 160 & 5.5 & 180 & 74.5 \\
\hline 85 & 20 & 5 & 400 & 662 & 1157 & 160 & 5.5 & 3 & 28.9 \\
\hline
\end{tabular}


(continued from previous page)

\begin{tabular}{|c|c|c|c|c|c|c|c|c|c|}
\hline S. number & $\begin{array}{l}\text { FA } \\
(\%)\end{array}$ & $\begin{array}{l}\text { SF } \\
(\%)\end{array}$ & $\begin{array}{l}\text { TCM } \\
\left(\mathrm{kg} / \mathrm{m}^{3}\right)\end{array}$ & $\begin{array}{l}\mathrm{ssa} \\
\left(\mathrm{kg} / \mathrm{m}^{3}\right)\end{array}$ & $\begin{array}{l}\mathrm{ca} \\
\left(\mathrm{kg} / \mathrm{m}^{3}\right)\end{array}$ & $\begin{array}{l}\mathrm{W} \\
\left(\mathrm{lt} / \mathrm{m}^{3}\right)\end{array}$ & $\begin{array}{l}\text { HRWRA } \\
\left(\mathrm{lt} / \mathrm{m}^{3}\right)\end{array}$ & $\begin{array}{l}\text { Age } \\
\text { (days) }\end{array}$ & $\begin{array}{l}\text { fc } \\
(\mathrm{MPa})\end{array}$ \\
\hline 86 & 20 & 5 & 400 & 662 & 1157 & 160 & 5.5 & 7 & 42.1 \\
\hline 87 & 20 & 5 & 400 & 662 & 1157 & 160 & 5.5 & 28 & 62.3 \\
\hline 88 & 20 & 5 & 400 & 662 & 1157 & 160 & 5.5 & 56 & 69.9 \\
\hline 89 & 20 & 5 & 400 & 662 & 1157 & 160 & 5.5 & 90 & 72.4 \\
\hline 90 & 20 & 5 & 400 & 662 & 1157 & 160 & 5.5 & 180 & 76 \\
\hline 91 & 40 & 5 & 400 & 636 & 1157 & 160 & 6 & 3 & 14.5 \\
\hline 92 & 40 & 5 & 400 & 636 & 1157 & 160 & 6 & 7 & 20.5 \\
\hline 93 & 40 & 5 & 400 & 636 & 1157 & 160 & 6 & 28 & 44.6 \\
\hline 94 & 40 & 5 & 400 & 636 & 1157 & 160 & 6 & 56 & 55.3 \\
\hline 95 & 40 & 5 & 400 & 636 & 1157 & 160 & 6 & 90 & 59.1 \\
\hline 96 & 40 & 5 & 400 & 636 & 1157 & 160 & 6 & 180 & 68.4 \\
\hline 97 & 0 & 0 & 410 & 609 & 1132 & 205 & 0 & 3 & 26.1 \\
\hline 98 & 0 & 0 & 410 & 609 & 1132 & 205 & 0 & 7 & 36.9 \\
\hline 99 & 0 & 0 & 410 & 609 & 1132 & 205 & 0 & 28 & 50.8 \\
\hline 100 & 0 & 0 & 410 & 609 & 1132 & 205 & 0 & 56 & 57.1 \\
\hline 101 & 0 & 0 & 410 & 609 & 1132 & 205 & 0 & 90 & 58.1 \\
\hline 102 & 0 & 0 & 410 & 609 & 1132 & 205 & 0 & 180 & 60.6 \\
\hline 103 & 15 & 0 & 410 & 589 & 1132 & 205 & 0 & 3 & 23.3 \\
\hline 104 & 15 & 0 & 410 & 589 & 1132 & 205 & 0 & 7 & 32.3 \\
\hline 105 & 15 & 0 & 410 & 589 & 1132 & 205 & 0 & 28 & 48.9 \\
\hline 106 & 15 & 0 & 410 & 589 & 1132 & 205 & 0 & 56 & 55.7 \\
\hline 107 & 15 & 0 & 410 & 589 & 1132 & 205 & 0 & 90 & 62.6 \\
\hline 108 & 15 & 0 & 410 & 589 & 1132 & 205 & 0 & 180 & 64.8 \\
\hline 109 & 25 & 0 & 410 & 576 & 1132 & 205 & 0 & 3 & 18.4 \\
\hline 110 & 25 & 0 & 410 & 576 & 1132 & 205 & 0 & 7 & 26.2 \\
\hline 111 & 25 & 0 & 410 & 576 & 1132 & 205 & 0 & 28 & 41.7 \\
\hline 112 & 25 & 0 & 410 & 576 & 1132 & 205 & 0 & 56 & 49.1 \\
\hline 113 & 25 & 0 & 410 & 576 & 1132 & 205 & 0 & 90 & 53.7 \\
\hline 114 & 25 & 0 & 410 & 576 & 1132 & 205 & 0 & 180 & 57.9 \\
\hline 115 & 45 & 0 & 410 & 549 & 1132 & 205 & 0 & 3 & 13.4 \\
\hline 116 & 45 & 0 & 410 & 549 & 1132 & 205 & 0 & 7 & 18.4 \\
\hline 117 & 45 & 0 & 410 & 549 & 1132 & 205 & 0 & 28 & 35.6 \\
\hline 118 & 45 & 0 & 410 & 549 & 1132 & 205 & 0 & 56 & 47 \\
\hline 119 & 45 & 0 & 410 & 549 & 1132 & 205 & 0 & 90 & 54.1 \\
\hline 120 & 45 & 0 & 410 & 549 & 1132 & 205 & 0 & 180 & 56.6 \\
\hline 121 & 55 & 0 & 410 & 536 & 1132 & 205 & 0 & 3 & 7.8 \\
\hline 122 & 55 & 0 & 410 & 536 & 1132 & 205 & 0 & 7 & 11.3 \\
\hline 123 & 55 & 0 & 410 & 536 & 1132 & 205 & 0 & 28 & 24 \\
\hline 124 & 55 & 0 & 410 & 536 & 1132 & 205 & 0 & 56 & 33.7 \\
\hline 125 & 55 & 0 & 410 & 536 & 1132 & 205 & 0 & 90 & 41.4 \\
\hline 126 & 55 & 0 & 410 & 536 & 1132 & 205 & 0 & 180 & 48.4 \\
\hline 127 & 0 & 5 & 410 & 605 & 1132 & 205 & 0 & 3 & 27.4 \\
\hline 128 & 0 & 5 & 410 & 605 & 1132 & 205 & 0 & 7 & 39.2 \\
\hline 129 & 0 & 5 & 410 & 605 & 1132 & 205 & 0 & 28 & 57.3 \\
\hline 130 & 0 & 5 & 410 & 605 & 1132 & 205 & 0 & 56 & 59.6 \\
\hline
\end{tabular}


(continued from previous page)

\begin{tabular}{|l|l|l|l|l|l|l|l|l|l|}
\hline S. number & $\begin{array}{l}\text { FA } \\
(\%)\end{array}$ & $\begin{array}{l}\text { SF } \\
(\%)\end{array}$ & $\begin{array}{l}\text { TCM } \\
\left(\mathrm{kg} / \mathrm{m}^{3}\right)\end{array}$ & $\begin{array}{l}\text { ssa } \\
\left(\mathrm{kg} / \mathrm{m}^{3}\right)\end{array}$ & $\begin{array}{l}\text { ca } \\
\left(\mathrm{kg} / \mathrm{m}^{3}\right)\end{array}$ & $\begin{array}{l}\text { W } \\
\left(\mathrm{lt} / \mathrm{m}^{3}\right)\end{array}$ & $\begin{array}{l}\text { HRWRA } \\
\left(\mathrm{lt} / \mathrm{m}^{3}\right)\end{array}$ & $\begin{array}{l}\text { Age } \\
(\text { days })\end{array}$ & $\begin{array}{l}\text { fc } \\
(\mathrm{MPa})\end{array}$ \\
\hline 131 & 0 & 5 & 410 & 605 & 1132 & 205 & 0 & 90 & 67.3 \\
\hline 132 & 0 & 5 & 410 & 605 & 1132 & 205 & 0 & 180 & 66.3 \\
\hline 133 & 20 & 5 & 410 & 578 & 1132 & 205 & 0 & 3 & 20.1 \\
\hline 134 & 20 & 5 & 410 & 578 & 1132 & 205 & 0 & 7 & 30.6 \\
\hline 135 & 20 & 5 & 410 & 578 & 1132 & 205 & 0 & 28 & 52.9 \\
\hline 136 & 20 & 5 & 410 & 578 & 1132 & 205 & 0 & 56 & 60.7 \\
\hline 137 & 20 & 5 & 410 & 578 & 1132 & 205 & 0 & 90 & 63.7 \\
\hline 138 & 20 & 5 & 410 & 578 & 1132 & 205 & 0 & 180 & 68 \\
\hline 139 & 40 & 5 & 410 & 552 & 1132 & 205 & 0 & 3 & 11.4 \\
\hline 140 & 40 & 5 & 410 & 552 & 1132 & 205 & 0 & 7 & 11.68 \\
\hline 141 & 40 & 5 & 410 & 552 & 1132 & 205 & 0 & 28 & 38.7 \\
\hline 142 & 40 & 5 & 410 & 552 & 1132 & 205 & 0 & 56 & 45.9 \\
\hline 143 & 40 & 5 & 410 & 552 & 1132 & 205 & 0 & 90 & 48.7 \\
\hline 144 & 40 & 5 & 410 & 552 & 1132 & 205 & 0 & 180 & 58.4 \\
\hline
\end{tabular}

Tab. 11: The RMSE values of ANN in training and testing phases (two-layer layer) (all data)

\begin{tabular}{|l|l|l|l|}
\hline $\begin{array}{l}\text { First } \\
\text { layer } \\
\text { neuron }\end{array}$ & $\begin{array}{l}\text { Second } \\
\text { layer } \\
\text { neuron }\end{array}$ & Train & Test \\
\hline 1 & 1 & 11.4671 & 15.89856 \\
\hline 2 & 1 & 8.077351 & 7.891446 \\
\hline 3 & 1 & 7.949106 & 8.088699 \\
\hline 4 & 1 & 5.949252 & 6.512514 \\
\hline 5 & 1 & 8.717519 & 9.439658 \\
\hline 6 & 1 & 5.882827 & 17.44543 \\
\hline 7 & 1 & 10.86265 & 21.58667 \\
\hline 8 & 1 & 3.519971 & 4.203522 \\
\hline 9 & 1 & 3.480376 & 4.148538 \\
\hline 10 & 1 & 7.612163 & 8.888949 \\
\hline 1 & 2 & 3.988789 & 5.743801 \\
\hline 2 & 2 & 7.023603 & 8.62837 \\
\hline 3 & 2 & 8.757661 & 9.98464 \\
\hline 4 & 2 & 4.429534 & 6.819625 \\
\hline 5 & 2 & 3.244493 & 4.099803 \\
\hline 6 & 2 & 3.02195 & 4.548377 \\
\hline 7 & 2 & 2.413124 & 3.971144 \\
\hline 8 & 2 & 1.794021 & 5.661613 \\
\hline 9 & 2 & 2.04402 & 3.212584 \\
\hline 10 & 2 & 3.205188 & 13.00973 \\
\hline 1 & 3 & 1.59428 & 7.433624 \\
\hline 2 & 3 & 2.605283 & 4.077756 \\
\hline 3 & 3 & 2.422984 & 5.601764 \\
\hline 4 & 3 & 1.486778 & 2.595376 \\
\hline 5 & 3 & 1.597706 & 4.780559 \\
\hline & $(c 0 n t i n e d$ & $09 n e x t$ & \\
\hline & 2 & & \\
\hline & 2 & & \\
\hline
\end{tabular}

(continued on next page) 
(continued from previous page)

\begin{tabular}{|c|c|c|c|}
\hline $\begin{array}{l}\text { first } \\
\text { layer } \\
\text { neuron }\end{array}$ & $\begin{array}{l}\text { second } \\
\text { layer } \\
\text { neuron }\end{array}$ & train & test \\
\hline 6 & 3 & 0.95611 & 5.570873 \\
\hline 7 & 3 & 1.042316 & 4.965718 \\
\hline 8 & 3 & 0.708144 & 14.35391 \\
\hline 9 & 3 & 1.539122 & 3.558423 \\
\hline 10 & 3 & 2.61746 & 6.872141 \\
\hline 1 & 4 & 1.847486 & 6.735188 \\
\hline 2 & 4 & 1.389969 & 6.713467 \\
\hline 3 & 4 & 0.644357 & 6.445502 \\
\hline 4 & 4 & 0.563873 & 10.68091 \\
\hline 5 & 4 & 0.95852 & 10.96912 \\
\hline 6 & 4 & 1.534524 & 2.208552 \\
\hline 7 & 4 & 0.914569 & 7.634039 \\
\hline 8 & 4 & 1.287565 & 4.734597 \\
\hline 9 & 4 & 1.163599 & 9.779257 \\
\hline 10 & 4 & 0.38738 & 19.30937 \\
\hline 1 & 5 & 1.148456 & 293.8489 \\
\hline 2 & 5 & 0.264395 & 17.6362 \\
\hline 3 & 5 & 1.106133 & 3.357923 \\
\hline 4 & 5 & 8.895453 & 10.03507 \\
\hline 5 & 5 & 0.619114 & 7.448675 \\
\hline 6 & 5 & 0.281349 & 7.574561 \\
\hline 7 & 5 & 0.235413 & 9.081563 \\
\hline 8 & 5 & 0.158538 & 44.88652 \\
\hline 9 & 5 & $9.53 \mathrm{E}-07$ & 6.451442 \\
\hline 10 & 5 & 1.313994 & 3.45978 \\
\hline 1 & 6 & 1.082255 & 13.1393 \\
\hline 2 & 6 & 0.396487 & 9.661204 \\
\hline 3 & 6 & 0.060666 & 8.296369 \\
\hline 4 & 6 & 0.047403 & 13.88591 \\
\hline 5 & 6 & $2.49 \mathrm{E}-07$ & 9.379142 \\
\hline 6 & 6 & $2.70 \mathrm{E}-09$ & 14.28784 \\
\hline 7 & 6 & 1.095173 & 5.670521 \\
\hline 8 & 6 & 0.224708 & 12.72747 \\
\hline 9 & 6 & 0.004833 & 5.593437 \\
\hline 10 & 6 & $2.09 \mathrm{E}-08$ & 8.372776 \\
\hline 1 & 7 & 0.107252 & 30.53993 \\
\hline 2 & 7 & $5.90 \mathrm{E}-10$ & 9.585075 \\
\hline 3 & 7 & $4.15 \mathrm{E}-09$ & 9.668321 \\
\hline 4 & 7 & 0.551107 & 7.367329 \\
\hline 5 & 7 & 0.259927 & 5.803591 \\
\hline 6 & 7 & 0.053599 & 6.389661 \\
\hline 7 & 7 & $1.08 \mathrm{E}-06$ & 8.827009 \\
\hline 8 & 7 & $1.08 \mathrm{E}-10$ & 5.963369 \\
\hline 9 & 7 & $6.19 \mathrm{E}-10$ & 25.21877 \\
\hline
\end{tabular}


(continued from previous page)

\begin{tabular}{|l|l|l|l|}
\hline $\begin{array}{l}\text { first } \\
\text { layer } \\
\text { neuron }\end{array}$ & $\begin{array}{l}\text { second } \\
\text { layer } \\
\text { neuron }\end{array}$ & train & test \\
\hline 10 & 7 & $1.27 \mathrm{E}-08$ & 5.772461 \\
\hline
\end{tabular}

74 "This is an Open Access article distributed under the terms of the Creative Commons Attribution License, which permits unrestricted use, distribution, and reproduction in any medium provided the original work is 